\title{
Alongshore Variability of Shoaling Internal Bores on the Inner Shelf
}

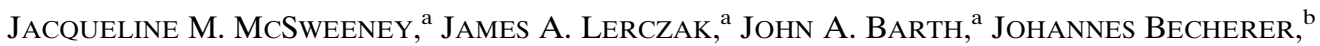 \\ Jennifer A. MACKinnon, ${ }^{c}$ Amy F. WATERhouse, ${ }^{c}$ John A. Colosi, ${ }^{d}$ JAmie H. MacMahan, ${ }^{d}$

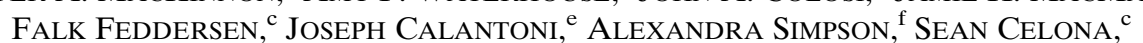 \\ MERrick C. HALlER, ${ }^{f}$ AND ERIC TERrill ${ }^{\mathrm{c}}$ \\ ${ }^{\mathrm{a}}$ College of Earth, Ocean, and Atmospheric Sciences, Oregon State University, Corvallis, Oregon; ${ }^{\mathrm{b}}$ Helmholtz-Zentrum Geesthacht, \\ Center for Materials and Coastal Research, Geesthacht, Germany; ${ }^{\mathrm{c}}$ Scripps Institution of Oceanography, University of California, \\ San Diego, La Jolla, California; ${ }^{\mathrm{d}}$ Department of Oceanography, Naval Postgraduate School, Monterey, California; ${ }^{\mathrm{e}}$ Ocean Sciences \\ Division, U.S. Naval Research Laboratory, Stennis Space Center, Mississippi; ${ }^{\mathrm{f}}$ School of Civil and Construction Engineering,
} Oregon State University, Corvallis, Oregon

(Manuscript received 29 April 2020, in final form 27 July 2020)

\begin{abstract}
Temperature and velocity measurements from 42 moorings were used to investigate the alongshore variability of nonlinear internal bores as they propagated across the central California inner shelf. Moorings were deployed September-October 2017 offshore of the Point Sal headland. Regional coverage was $\sim 30 \mathrm{~km}$ alongshore and $\sim 15 \mathrm{~km}$ across shore, spanning 9-100-m water depths. In addition to subtidal processes modulating regional stratification, internal bores generated complex spatiotemporal patterns of stratification variability. Internal bores were alongshore continuous on the order of tens of kilometers at the $50-\mathrm{m}$ isobath, but the length scales of frontal continuity decreased to $O(1 \mathrm{~km})$ at the $25-\mathrm{m}$ isobath. The depth-averaged, bandpass-filtered (from $3 \mathrm{~min}$ to $16 \mathrm{~h}$ ) internal bore kinetic energy $\left(\overline{\mathrm{KE}_{\mathrm{IB}}}\right)$ was found to be nonuniform along a bore front, even in the case of an alongshorecontinuous bore. The pattern of along-bore $\overline{\mathrm{KE}_{\mathrm{IB}}}$ variability varied for each bore, but a 2-week average indicated that $\overline{\mathrm{KE}_{\mathrm{IB}}}$ was generally strongest around Point Sal. The stratification ahead of a bore influenced both the bore's amplitude and cross-shore evolution. The data suggest that alongshore stratification gradients can cause a bore to evolve differently at various alongshore locations. Three potential bore fates were observed: 1) bores transiting intact to the 9-m isobath, 2) bores being overrun by faster, subsequent bores, leading to bore-merging events, and 3) bores disappearing when the upstream pycnocline was near or below middepth. Maps of hourly stratification at each mooring and the estimated position of sequential bores demonstrated that an individual internal bore can significantly impact the waveguide of the subsequent bore.
\end{abstract}

KEYWORDS: Continental shelf/slope; Internal waves; Nonlinear dynamics; Wave properties

\section{Introduction}

Internal waves are globally ubiquitous in the coastal ocean and contribute substantially to mixing and cross-shelf fluxes of water properties, water-borne materials, and energy in inner shelf regions. Internal waves are also a critical factor affecting acoustic propagation, with important implications for underwater communication, navigation, and remote sensing (Duda et al. 2012; Lin et al. 2012, 2013). As internal waves encounter shallowing water depths while propagating across the inner shelf, a region that lies between the surfzone and the midcontinental shelf (Lentz and Fewings 2012), their frontal shape can evolve significantly. Coastal internal waves are often highly nonlinear, and their cross-shelf evolution during shoaling is strongly dependent on the bottom topography, background currents, and shelf stratification they propagate into (i.e., the upstream waveguide). Though internal waves have been observed in many regions worldwide, it is challenging to collect measurements that resolve their evolution during shoaling. Thus, the bulk of our knowledge of shoaling dynamics is informed by numerical models, weakly nonlinear theory, and

Corresponding author: Jacqueline McSweeney, jack.mcsweeney@ oregonstate.edu laboratory experiments (e.g., Lee and Beardsley 1974; Helfrich and Melville 1986; Grimshaw et al. 2002; Scotti et al. 2007; Alford et al. 2010; Grimshaw et al. 2014; Ostrovsky and Helfrich 2019).

As our observational capacities have improved, so has our ability to monitor shoaling internal waves. Notable datasets of internal waves have emerged, such as those from the South China Sea (Ramp et al. 2004; Alford et al. 2010), Massachusetts Bay (Butman et al. 2006; Scotti et al. 2007), the New Jersey Shelf (Tang et al. 2007; Shroyer et al. 2011), and the California inner shelf (Lerczak et al. 2003; Walter et al. 2012; Lerczak et al. 2019). From these observations, a myriad of topics related to shoaling internal waves have been investigated: how the upstream waveguide influences a bore's evolution, polarity reversals of high-frequency internal waves, and changes in bore speed across the shelf. Our understanding of internal wave dynamics has improved, but there are lingering uncertainties about which processes most strongly influence the properties and evolution of shoaling internal waves. The main drivers of bore-to-bore variability of internal wave properties under similar subtidal shelf conditions are also unknown. Understanding these dynamics is key to quantifying the contribution of internal waves to mixing, transport, and stratification variability on the shelf.

Most studies about cross-shore propagating internal waves have been conducted in a two-dimensional (2D) cross-shore 
framework, ignoring alongshore variability of internal bores. However, from nearshore in situ observations of internal waves, we know that temperature and stratification variability associated with internal waves can vary alongshore (Cudaback and McPhee-Shaw 2009; Aristizábal et al. 2016; Feddersen et al. 2020). Remote sensing platforms, both satellite and shore-based, also illustrate that internal bores can have complex alongfront structure (Vlasenko and Stashchuk 2007; Badiey et al. 2013; Lerczak et al. 2019). Moving beyond the traditional cross-shelf framework, the coastal oceanographic community has recently started considering the $3 \mathrm{D}$ processes involved in internal wave shoaling. For example, a numerical modeling study focused on the influence of $2 \mathrm{D}$ nonuniform bathymetry on shoaling internal waves demonstrates that horizontal wave refraction generates regions of concavity and convexity along a bore front that can lead to a redistribution of energy along the wave (Vlasenko and Stashchuk 2007). In Massachusetts Bay, internal wave properties such as speed and high-frequency wave energy vary in both the alongshore and cross-shore directions (Thomas et al. 2016). Though only a few studies have investigated the 3D nature of internal waves, the topic has significant implications for the contribution of internal waves to shelf properties and cross-shelf transport.

In this paper, we examine the alongshore variability of internal waves propagating shoreward across the central California inner shelf. Internal tides are a significant driver of stratification variability in this region (Aristizábal et al. 2016; Colosi et al. 2018; McSweeney et al. 2020), but the spatiotemporal variability of their influence remains unknown. Two internal bores arrive within every semidiurnal period, though only about half of the bores observed at the 50-m isobath are detectable at the $10-\mathrm{m}$ isobath (McSweeney et al. 2020). The mechanisms impeding bores from surviving to shore is unknown. Nearshore observations in 9-16-m water depths suggest that the alongshore decorrelation length scale of semidiurnal temperature is $\sim 7.5 \mathrm{~km}$ and that the associated vertical temperature structure varies significantly alongshore (Feddersen et al. 2020). In contrast, regional observations farther offshore and a numerical model suggest larger length scales of alongshore coherence of semidiurnal baroclinic energy fluxes at the 50-m isobath (Kumar et al. 2019). The dynamics that cause the decreasing length scales of alongshore semidiurnal coherence across the inner shelf remain unknown.

The 2017 Inner Shelf Dynamics Experiment (Lerczak et al. 2019) entailed unprecedented in situ data coverage of internal bores across a $450-\mathrm{km}^{2}$ region of the central California inner shelf. The spatial and temporal resolution of the data provide a unique opportunity to study the alongshore variability of internal bores as they evolve while transiting across shallowing topography. We explored how internal bores are both influenced by and contribute to shelf stratification variability. Throughout the discussion, the term "continuous" is used to describe internal bores that have a frontal feature qualitatively observable alongshore, while the term "coherent" describes internal bore features that are statistically correlated alongshore. We observed that kinetic energy along an $\sim 30-\mathrm{km}$ alongshore-continuous bore front was nonuniform, and the along-bore kinetic energy patterns varied at an event scale. From a comparison of the evolution of individual bores at

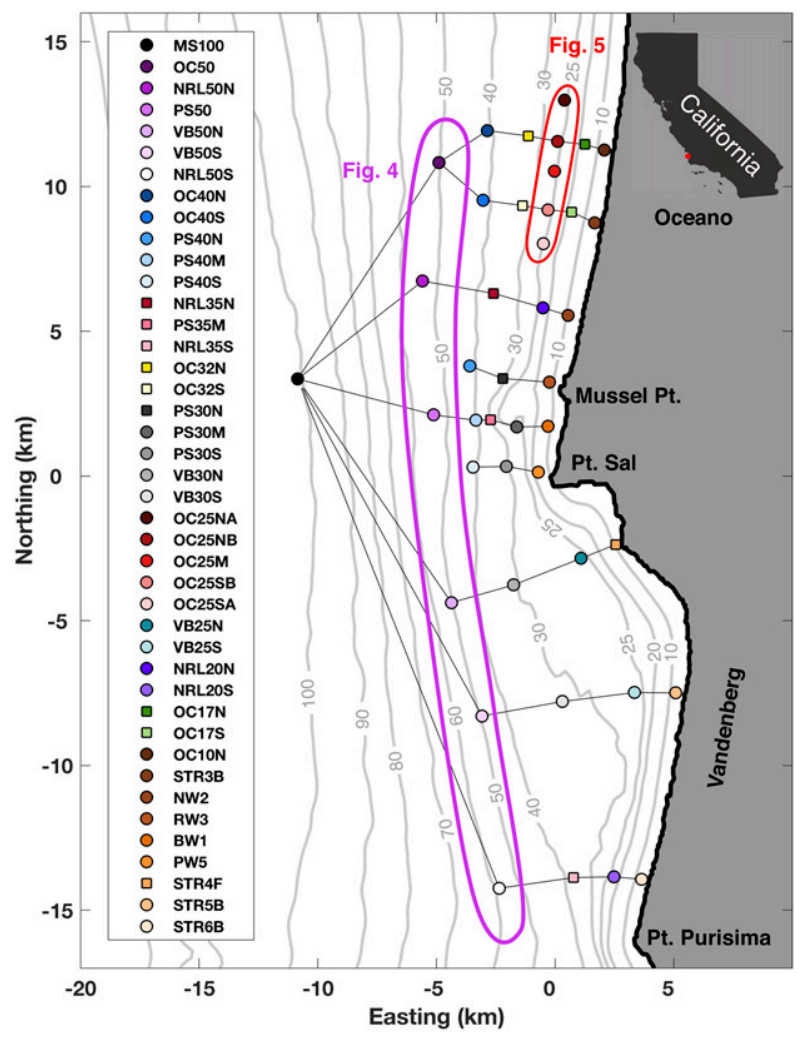

FIG. 1. Map depicting the 42 moorings where both velocity and temperature (circles) and only temperature (squares) data were available. For MS100-OC10N in the legend, the numbers in the site name indicate the water depth at that location. For STR3BSTR6B, the deployment depths were $\sim 9-13 \mathrm{~m}$. The thin black lines denote the cross-shore transects used for mapping the bores, as described in section $2 \mathrm{c}(3)$.

several cross-shelf transects, we found that alongshore stratification variability can generate along-bore heterogeneity in the frontal shape, amplitude, and cross-shore evolution. Hourly maps of bore position and stratification illustrated that individual bores influenced local stratification variability, thus impacting the subsequent bore.

\section{Methods}

\section{a. Study site}

The study site is located on the midshelf and inner shelf within the Santa Maria Basin of central California (Fig. 1). It is centered on Point Sal, spanning $\sim 30 \mathrm{~km}$ along shelf and extending from Oceano to Point Purisima. Notably, the region encompasses a range of topographic and shoreline features. Near Oceano, north of Point Sal, the coastline is relatively straight and the cross-shelf topography is approximately planar. A few kilometers north of Point Sal, there is a small headland (Mussel Point) and a submerged rocky outcrop 2$3 \mathrm{~km}$ offshore. Point Sal is a large rocky headland, and farther south at Vandenberg the coastline is concave with a milder cross-shelf slope than the Oceano region. The cross-shelf 
TABLE 1. Summary of shelf slope estimates $(\Delta z / \Delta x)$ at three cross-shore locations based on the distance between the 50- and $10-\mathrm{m}$ isobaths and the 40- and $25-\mathrm{m}$ isobaths. The difference between the two estimates for each region is also provided.

\begin{tabular}{|c|c|c|c|c|c|}
\hline Region & $\begin{array}{l}\text { Approximate distance } \\
\text { between } 50-\text { and } 10-\mathrm{m} \\
\text { isobaths }(\mathrm{km})\end{array}$ & $\begin{array}{l}\text { Approximate shelf slope } \\
\text { between } 50-\text { and } 10-\mathrm{m} \\
\text { isobaths }\left(s_{1}\right)\end{array}$ & $\begin{array}{l}\text { Approximate distance } \\
\text { between } 40-\text { and } 25-\mathrm{m} \\
\text { isobaths }(\mathrm{km})\end{array}$ & $\begin{array}{l}\text { Approximate shelf slope } \\
\text { between } 40-\text { and } 25-\mathrm{m} \\
\text { isobaths }\left(s_{2,}\right)\end{array}$ & $\begin{array}{l}\Delta \text { Slope } \\
\left(s_{1}-s_{2}\right)\end{array}$ \\
\hline Oceano & 6.7 & 0.0060 & 3.0 & 0.0050 & 0.0010 \\
\hline Point Sal & 4.5 & 0.0089 & 2.4 & 0.0063 & 0.0026 \\
\hline Vandenberg & 8.0 & 0.0050 & 5.4 & 0.0028 & 0.022 \\
\hline
\end{tabular}

slopes based on the distance between the 50- and 10 -m isobaths are 0.0060 at Oceano, 0.0089 at Point Sal, and 0.0050 at Vandenberg (Table 1). The slopes estimated from the separation of the $40-$ and $25-\mathrm{m}$ isobaths are $0.0050,0.0063$, and 0.0028 , respectively.

The bathymetric slopes in this region are generally subcritical (Kumar et al. 2019), but the criticality changes in time with stratification. The slope criticality parameter $\gamma$ is calculated by

$$
\begin{aligned}
\gamma & =|\nabla h|\left(\frac{\omega^{2}-f^{2}}{N_{b}^{2}-\omega^{2}}\right)^{-1 / 2}, \text { with } \\
\nabla h & =\sqrt{(\partial h / \partial x)^{2}+(\partial h / \partial y)^{2}},
\end{aligned}
$$

where $h$ is the water depth, $\omega$ is the M2 frequency, $f$ is the Coriolis frequency, and $N_{b}^{2}$ is the squared buoyancy frequency near the bed (Regal and Wunsch 1973; Lerczak et al. 2003; Garrett and Kunze 2007; Buijsman et al. 2012; Kumar et al. 2019). We calculated $\gamma$ at each mooring and confirmed that the time-averaged $\gamma$ is indeed subcritical at all of the mooring sites. Although $\gamma$ is subtidally modulated by the evolving stratification, it remains subcritical throughout the observational period at sites deeper than $15 \mathrm{~m}$. At the nearshore sites $(<10 \mathrm{~m}), \gamma$ was supercritical in early to mid-September and then subcritical late September and onward. We note that $\gamma$ estimates north of Point Sal were an order of magnitude smaller $(\sim 0.011)$ than those south of Point Sal $(\sim 0.11)$ as a result of alongshore differences in $\nabla h$.

\section{b. Observational data}

We utilized 42 moorings from the Inner Shelf Dynamics Experiment (Lerczak et al. 2019) that were deployed from 6 September to 2 November 2017. These moorings spanned 9-100-m water depths, with variable horizontal spacing ranging from 1 to $5 \mathrm{~km}$ (Fig. 1). While most moorings included an upward-looking ADCP and a string of thermistors vertically separated by 1-2 $\mathrm{m}$ (Fig. 1, circles), the details of mooring configurations varied (McSweeney et al. 2020; Feddersen et al. $2020)$. Since salinity varied minimally $(<0.35 \mathrm{psu})$ within the region during the observational period (McSweeney et al. 2020), temperature was the main driver of density variability and a mean salinity was used to compute density.

Data processing details can be found in McSweeney et al. (2020), which we briefly summarize. For all moorings, the velocity, temperature, and density data were extrapolated to the surface and bed using a quadratic polynomial regression and assuming no shear at the boundaries. Extrapolations were carried out in sigma, surface-following coordinates, which is important nearshore where the tidal range is $\sim 10 \%$ of the water column. Temporal gaps of $<5 \mathrm{~min}$ were filled by linear interpolation, and the data were averaged to 1-min resolution. Bore arrivals at each mooring were identified with an isopycnal displacement criteria, which uses three isopycnals to track when the pycnocline is rapidly displaced downward from its background position. The bore identification method intentionally focuses on internal bores of depression and is conservative in excluding questionable cases.

\section{c. Data analysis}

\section{1) Methods to Describe STRATIFICATION}

A primary aim is to understand how internal bores are both influenced by and contribute to shelf stratification variability. Consequently, several methods were used to quantify stratification. Most simply, we calculated the temperature difference between the surface and bed $\Delta T$. Additionally, we estimated the mode-1 longwave linear phase speed $c_{o}$ and the nonlinearity coefficient of the Korteweg-de Vries (KdV) equation (Lee and Beardsley 1974; Grimshaw et al. 1997) $\alpha$ as metrics for stratification.

Estimates of $c_{o}$ and $\alpha$ are calculated from the following eigenvalue problem, which excludes the effects of rotation and background shear:

$$
\begin{aligned}
\frac{d^{2} \phi}{\partial z^{2}}+\frac{N^{2}(z)}{\left(c_{o}\right)^{2}} \phi & =0 \text { and } \\
\alpha & =\frac{3 \int_{-H}^{0}\left(c_{o}\right)^{2}\left(\frac{\partial \phi}{\partial z}\right)^{3} d z}{2 \int_{-H}^{0} c_{o}\left(\frac{\partial \phi}{\partial z}\right)^{2} d z},
\end{aligned}
$$

where $\phi$ is the vertical structure function for vertical velocity, $z$ is the vertical coordinate, $N^{2}$ is the squared buoyancy frequency, and $H$ is the total water depth. Both rotation (Grimshaw and Helfrich 2012; Grimshaw et al. 2014; Ostrovsky and Helfrich 2019) and background shear (Stastna and Lamb 2002; Walter et al. 2016) can significantly impact the evolution of internal tides, but we exclude them here to focus on the influences of stratification variability.

Estimates of $\alpha$ provide insight about the vertical density structure (Holloway et al. 1997; Grimshaw et al. 1997) and its influence on shoaling internal bores (Scotti et al. 2008; McSweeney et al. 2020). The sign of $\alpha$ generally indicates the vertical position of the pycnocline relative to middepth, where the pycnocline is located above middepth when $\alpha$ is 
positive and where the pycnocline is below middepth $\alpha$ is negative for a two-layer system. At the outer shelf, bores of depression propagate toward shore when $\alpha$ is positive. Both observations (McSweeney et al. 2020) and modeling studies (Scotti et al. 2008) have demonstrated that an internal bore will maintain a sharp front when propagating into a positive $\alpha$ environment but that it will begin to rarefy (decrease in frontal sharpness) in the case of a negative upstream $\alpha$.

Calculations of $c_{o}$ and $\alpha$ are both sensitive to the definition of "background density" from which $N^{2}$ is calculated, so we calculated $c_{o}$ and $\alpha$ using three different estimates of the density: the 1-min, prebore, and subtidal. For the prebore density, we averaged the density profile over the $30 \mathrm{~min}$ preceding a bore arrival. For the subtidal density, we chose a method similar to the calculation of background potential energy (e.g., Winters et al. 1995) to minimize the influences of internal waves. We numerically sorted all density values within a 24.84-h moving window and scaled the stable density profile to the water depth.

In contrast, we estimated subtidal $\Delta T$ by low-pass filtering the 1 -min $\Delta T$ with a 33 -h cutoff. To estimate a prebore $\Delta T$, we took a 30-min average of the temperature profile before a bore's arrival and then calculated the difference between the surface and bottom values.

\section{2) CAlCUlating INTERNAL BORE KINETIC ENERGY}

For the kinetic energy analysis, the depth mean was removed from the velocity data and the remaining baroclinic component was bandpass filtered with 3-min and 16-h cutoffs to isolate the internal bore signal, which includes both semidiurnal and high frequency. Although the depth mean is not always sufficient for isolating barotropic currents in shallow water (Edwards and Seim 2008), in these data the baroclinic signals are so prominent after bandpass filtering that there is negligible difference between the kinetic energy estimates calculated from the total and depth-mean-removed velocities. The chosen 3-min-16-h filtering band is wider than that used in other studies, such as the 10-16-h semidiurnal bandpass filter used in Feddersen et al. (2020). We specifically included the higher-frequency component because energy associated with the semidiurnal internal tide may be manifested in higher frequencies due to the highly nonlinear nature of shoaling internal waves (e.g., Holloway et al. 1997; Colosi et al. 2018).

We estimated the depth-averaged, internal bore energy as

$$
\overline{\mathrm{KE}_{\mathrm{IB}}}=\overline{\frac{1}{2} \rho\left(u^{2}+v^{2}+w^{2}\right)},
$$

where $\rho$ is the density; the overbar denotes depth averaging; and $u, v$, and $w$ are the eastward, northward, and vertical bandpass-filtered baroclinic velocities. For our time-averaged $\mathrm{KE}$ analysis, we focused on 10-22 September to avoid bias from later data gaps.

\section{3) MAPPING THE INTERNAL BORES}

Using the arrival times of each bore at all the moorings, we generated maps of the estimated bore position at any given time. We linearly interpolated the bore arrival times across mooring-pair segments of nine cross-shore transects (Fig. 1, black lines). For example, at the southernmost transect, the bore arrival time was interpolated between the MS100, NRL50S, NRL35S, NRL20S, and STR6B moorings. This approach accounts for the observed cross-shore deceleration of the bores (McSweeney et al. 2020) in a piecewise sense, reasonably capturing the bores' speed. Connecting the bore position within each cross-shore transect, we constructed a time-varying, horizontal map of each bore that demonstrates the bore's alongshore shape and orientation. Since some bores disappeared while shoaling at some alongshore locations, comparing these maps to the in situ temperature and velocity data was necessary for interpretation.

\section{Results}

\section{a. Alongshore variability in stratification}

To quantify alongshore subtidal variability in stratification, we considered the subtidal $\Delta T, \alpha$, and $c_{o}$ over the observational period (Fig. 2). Unsurprisingly, $\Delta T$ and $c_{o}$ had similar time series at all locations, with a subtidal modulation that was distinct from that of $\alpha$. Stratification was strongest in early September, gradually decreased to a minimum in late September/early October, and then restrengthened in mid-October. Although the 50-m locations had similar subtidal patterns, alongshore stratification gradients were still evident. For example, on 11-12 September (Fig. 2., pink shading) stratification was strongest at VB50S, weakest at NRL50S, and had a midvalue at the other locations.

The vertical structure of stratification, described by $\alpha$, had similar subtidal modulation at each 50-m location, but the alongshore $\alpha$ gradient varied significantly on subtidal time scales (Fig. 2f). Subtidal $\alpha$ was positive at all six sites for some periods of time, such as 9-20 September and from 28 September to 2 October, indicating that the subtidal depth of pycnocline was above middepth along this $30-\mathrm{km}$ stretch of the $50-\mathrm{m}$ isobath. At other times, for instance 6-10 October, $\alpha$ was negative at all locations and the subtidal position of the pycnocline was below middepth along the 50-m isobath. However, even when the sign of $\alpha$ was consistent alongshore, the magnitude $\alpha$ could vary significantly at the 50-m moorings. These alongshore $\alpha$ gradients have important implications, as alongshore variability in the waveguide likely introduces alongshore variability to a bore during shoaling even if the bore has an alongshore-continuous front offshore.

To evaluate the sensitivity of the stratification metrics to the different definitions of background density, we compared the subtidal, prebore, and 1-min estimates for $\alpha, c_{o}$, and $\Delta T$ at the OC50 mooring site (Fig. 3). Findings were similar for all 50-m moorings. High-frequency variability in the stratification strength, as is evident in $\Delta T$ and $c_{o}$, was relatively small in comparison with subtidal variability (Figs. 3a,b). However, the high-frequency variability of $\alpha$ was larger than subtidal variability (Fig. 3c). The variance of the 1 -min $\alpha$ was $3.6 \times 10^{-6} \mathrm{~s}^{-1}$ (Fig. 3c, gray line) as compared with $1.4 \times 10^{-6} \mathrm{~s}^{-1}$ for the subtidal $\alpha$ (Fig. 3c, black line), implying that internal waves modify the vertical density structure more so than subtidal processes.

\section{b. Length scales of alongshore continuity of internal bores}

The alongshore length scales of internal bore continuity are evident in a $27-\mathrm{h}$ time series of the semidiurnal (16-h high-pass filtered) eastward baroclinic velocities and 1-min temperature 


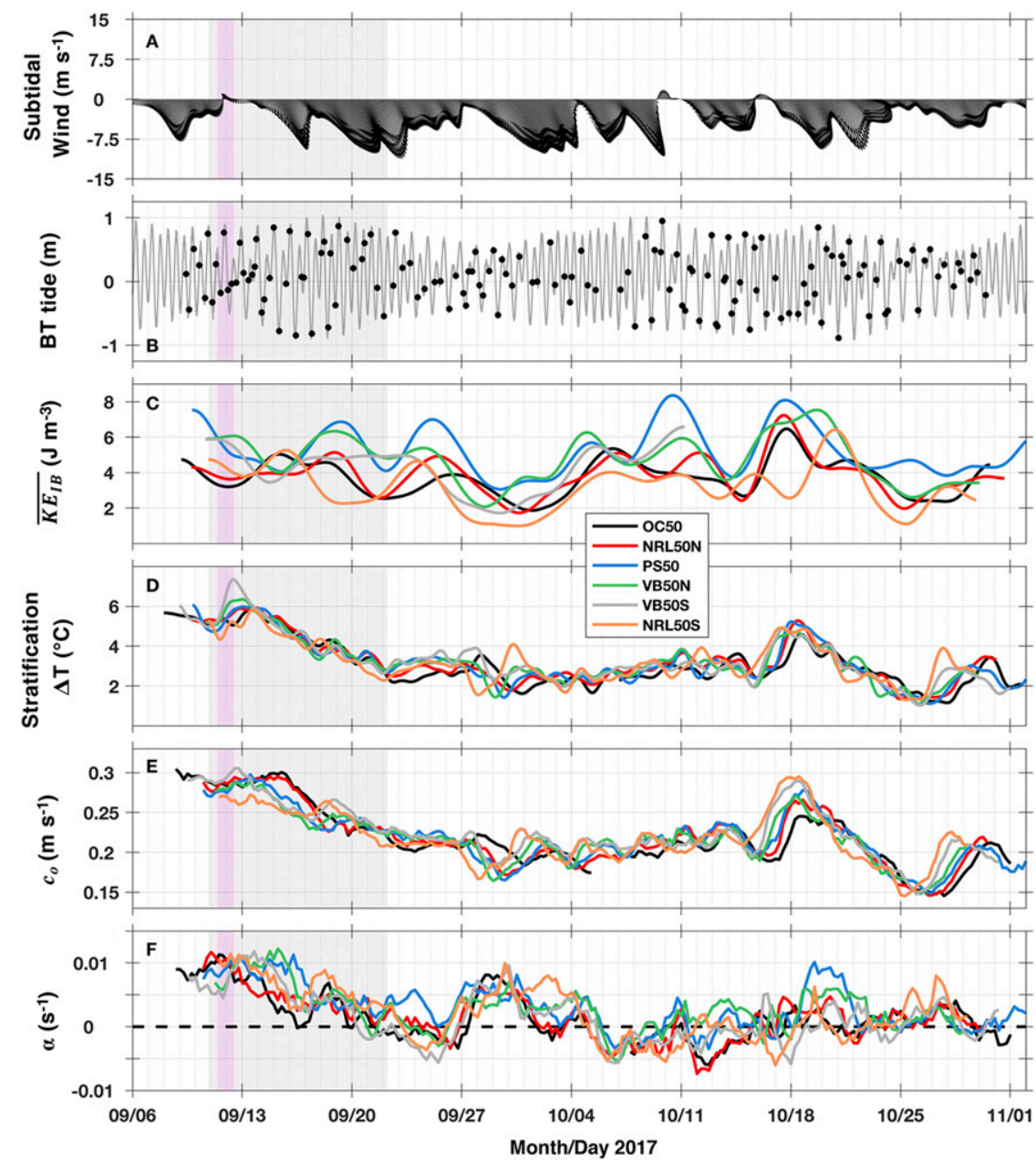

FIG. 2. (a) Subtidal winds ( $\mathrm{m} \mathrm{s}^{-1} ; 33$-h low-pass filtered) from the NDBC Santa Maria Buoy 46011. (b) The barotropic tide ( $\mathrm{m}$; gray line) and arrival times of internal bores at OC50 (black dots). (c) Four-day low-pass-filtered depth-averaged internal bore kinetic energy $\left(\overline{\mathrm{KE}_{\mathrm{IB}}}\right)$ ( $\mathrm{J} \mathrm{m}^{-3} ; 3$-min-16-h bandpass filtered) for all of the 50-m moorings. (d) Subtidal $\Delta T\left({ }^{\circ} \mathrm{C}\right)$, the difference between surface and bottom temperatures as calculated in section $2 \mathrm{c}(1)$. The (e) nonrotating longwave linear phase speed $\left(\mathrm{m} \mathrm{s}^{-1}\right)$ and (f) $\alpha\left(\mathrm{s}^{-1}\right)$ estimated from the subtidal density field at each 50-m mooring. Gray shading indicates the period used for the kinetic energy analysis (section 3c), and pink shading indicates the period used for the continuity and cross-shore evolution analyses (sections $3 \mathrm{~b}$ and $3 \mathrm{~d}$, respectively).

data for all the 50-m moorings (Fig. 4), which were each spaced $\sim 5 \mathrm{~km}$ apart alongshore (Fig. 1). Four bores transited past the $50-\mathrm{m}$ isobath during this time (arrivals denoted by triangles in Fig. 4), with three of the four arriving first at the VB50N location. For simplicity, we will henceforth refer to these sequential bores as B1, B2, B3, and B4 and denote their passage by colored triangles-green, blue, pink, and purple, respectively.

All four bores were apparent at each of the six 50-m mooring locations, spanning an alongshore distance of $\sim 30 \mathrm{~km}$. However, each had unique alongshore variability in bore structure. B1 had a sharp front at all locations, with high-frequency waves present at the northern sites. Near Point Sal, the front appeared to be more rarefied (i.e., less sharp), which was evident from the depressions of the $13^{\circ}, 14^{\circ}$, and $15^{\circ} \mathrm{C}$ isotherms being offset in time. B2 was similarly more undular in the north, with a more rarified front near Point Sal (PS50). However, while B1 propagated into an upstream current that was fairly alongshore uniform and characterized by offshore surface flows and onshore flows at depth, B2 transited into an upstream surface current that was directed offshore at the northern sites but onshore at PS50 and southward (Fig. 4). The onshore surface current ahead of B2 at PS50-NRL50S suggests that B2 was beginning to merge with the back end of B1 (discussed further in section $3 \mathrm{~d}$ ). There was a sharp pycnocline displacement associated with the B2 passage, but the upstream waveguide was significantly influenced by the previous bore B1.

The third internal bore, B3, had an undular structure, though its shape varied alongshore. Though the upstream current was 


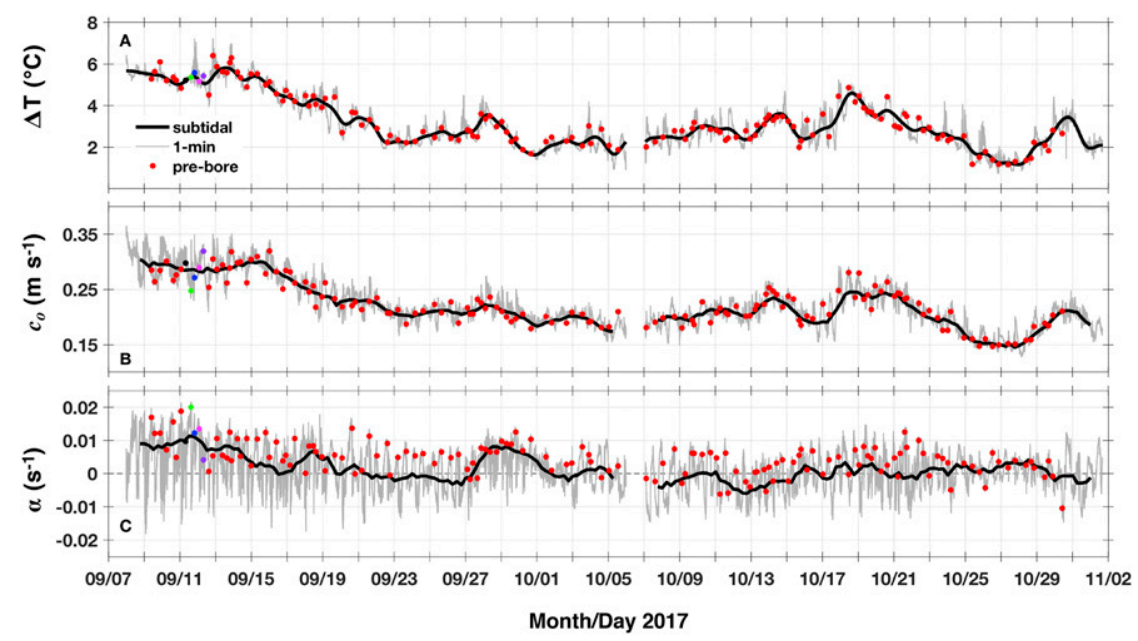

FIG. 3. (a) The vertical temperature difference $\Delta T\left({ }^{\circ} \mathrm{C}\right)$, (b) the nonrotating longwave linear phase speed $c_{o}\left(\mathrm{~m} \mathrm{~s}^{-1}\right)$, and (c) the nonlinearity $\mathrm{KdV}$ coefficient $\alpha\left(\mathrm{s}^{-1}\right)$ at OC50. The thick black line shows the estimate from the subtidal density product, the red dots show the estimates from the prebore averaged density [as done in McSweeney et al. (2020), their Figs. 8 and 13], and the thin gray lines show the estimates from the 1-min density data. For the B1-B4 bores, the prebore estimates are shown in green, blue, pink, and purple dots, respectively.

similar (offshore in surface layer, onshore below pycnocline) along the 50-m isobath, the vertical structure of stratification ahead of the bore arrival was not alongshore uniform (Fig. 4). B4, similar to B2, encountered an alongshore variable upstream current and stratification. For example, the upstream currents at PS50 and VB50N are strongly onshore in the surface layer and offshore at depth, while the upstream currents at NRL50N are relatively weak and directed offshore at the surface and onshore at depth. There is a distinct pycnocline at OC50 whereas the water column is more linearly stratified water at PS50. Bore B4 is clearly separated from B3 at OC50 and NRL50N, but B4 merges into the back of B3 southward from PS50. At the northern locations the B4 front was less sharp, an indicator the front may have been in the process of rarefying. The observations demonstrate that nonlinear internal bores may be alongshore continuous $O(30 \mathrm{~km})$ while having large alongshore variations in shape and magnitude.

As the four bores evolved while transiting into shallower water, the length scales of alongshore continuity shortened. From moorings spaced $\sim 1 \mathrm{~km}$ apart at the $25-\mathrm{m}$ isobath north of Point Sal (Fig. 5), we observed that a bore's shape could vary significantly on spatial scales $O(1 \mathrm{~km})$. For example, B1 at OC25SB included high-frequency waves that were less pronounced at OC25M and nonexistent at OC25NA. Additionally, we observed that an individual bore front could be discontinuous on these short length scales. For example, B2 was visible at the northern locations and became less pronounced (more rarefied) alongshore such that it was not identifiable at OC25SA. In contrast, B4 had a pronounced frontal feature at both the northernmost and southernmost locations, but was not identifiable at OC25M and OC25SB. Comparing $\mathrm{OC} 25 \mathrm{NB}$ and $\mathrm{OC} 25 \mathrm{M}$, we speculate that $\mathrm{B} 4$ merged into the back end of B3, obscuring the B4 frontal signature. Observations of alongshore discontinuity $O(1 \mathrm{~km})$ at the $25-\mathrm{m}$ isobath imply that length scales of alongshore bore continuity can decrease during shoaling.

\section{c. Kinetic energy of the internal bores}

There was a nearly linear cross-shore decrease in the depth-averaged internal bore kinetic energy averaged over 10-22 September $\left(\left\langle\overline{\mathrm{KE}_{\mathrm{IB}}}\right\rangle\right.$; Fig. 6a). Removing this trend in $\left\langle\overline{\mathrm{KE}_{\mathrm{IB}}}\right\rangle$ with water depth (the fitted line in Fig. 6a) revealed along-isobath variations in $\left\langle\overline{\mathrm{KE}_{\mathrm{IB}}}\right\rangle$ (Fig. 7b). For example, $\left\langle\overline{\mathrm{KE}_{\mathrm{IB}}}\right\rangle$ along the 50-m isobath was about 2-3 times greater near Point Sal (Fig. 6b), consistent with the subtidal pattern observed along the 50-m isobath (Fig. 2c).

The $\overline{\mathrm{KE}_{\mathrm{IB}}}$ associated with an individual bore was generally uncorrelated alongshore and there were no consistent patterns of alongshore $\overline{\mathrm{KE}_{\mathrm{IB}}}$ variability (Figs. $6 \mathrm{c}-\mathrm{h}$ ). Within this 12-day record, there were cases of the $\overline{\mathrm{KE}_{\mathrm{IB}}}$ being greatest 1 ) in the south with decreasing values toward the north (e.g., 10 September 2017), 2) around Point Sal with lesser values to the north and south (e.g., 13 September 2017), and 3) in the north with weaker but variable $\overline{\mathrm{KE}_{\mathrm{IB}}}$ to the south (e.g., 14 September 2017). The southernmost location, NRL50S, had the lowest average $\overline{\mathrm{KE}_{\mathrm{IB}}}$ but there were still occasional peaks that exceeded those at the other sites. The duration of the $\overline{\mathrm{KE}_{\mathrm{IB}}}$ peak associated with an individual bore passage also varied alongshore with no obvious pattern.

The alongshore coherence of $\overline{\mathrm{KE}_{\mathrm{IB}}}$ was quantified by calculating the squared correlation, $r^{2}$, at each mooring pair along the 50-m isobath (Fig. 7) utilizing data from 10 September to 11 October, a longer timeframe than shown in Fig. 6. Locations VB50N and VB50S were most correlated, with an $r^{2}$ value of 0.23 for the 1-16-h bandpassed KE. However, the rest of the $r^{2}$ values were $<0.15$, confirming our conclusion that the $\overline{\mathrm{KE}_{\mathrm{IB}}}$ at the 50-m isobath was largely uncorrelated. A lagged correlation analysis did not yield a higher $r^{2}$, likely due to the bore-to-bore variability in both 


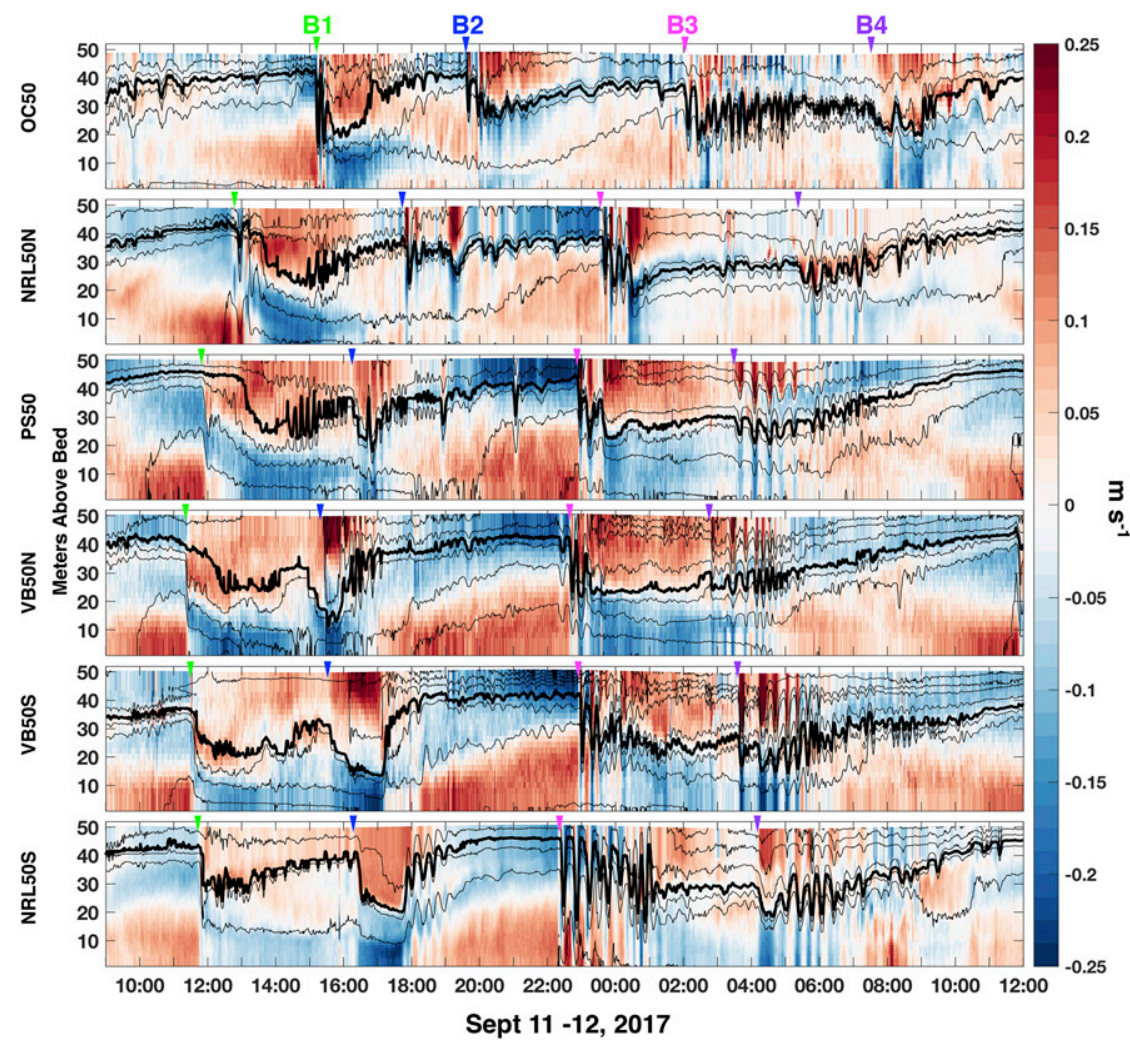

FIG. 4. The 16-h high-pass-filtered baroclinic eastward velocities $\left(\mathrm{m} \mathrm{s}^{-1}\right.$; colored, with positive values toward east) and temperature $\left({ }^{\circ} \mathrm{C}\right.$; black contours at $1^{\circ}$ intervals, with the $15^{\circ}$ isotherm thicker) from 11 to 12 Sep 2017 for the 50-m moorings from (top) north to (bottom) south, each spaced $\sim 5 \mathrm{~km}$ apart along-coast. Subsequent bores, B1-B4, are noted by green, blue, magenta, and purple triangles at each location.

the phasing of the bore arrivals at the alongshore locations and the alongshore $\overline{\mathrm{KE}_{\mathrm{IB}}}$ patterns.

The $\overline{\mathrm{KE}_{\mathrm{IB}}}$ time series indicated significant bore-to-bore variability in the alongshore kinetic energy of specific internal bores (Fig. 6). To better understand the alongshore variations of $\overline{\mathrm{KE}_{\mathrm{IB}}}$ of individual bores, we look at the $\overline{\mathrm{KE}_{\mathrm{IB}}}$ for the four bore cases discussed in section $3 \mathrm{~b}$ (Fig. 8), considering the bore-to-bore variability in the timing of the $\overline{\mathrm{KE}_{\mathrm{SD}}}$ peak relative to the bore arrival. For B1, $\overline{\mathrm{KE}_{\mathrm{IB}}}$ decreased from north to south and there was relatively little high-frequency energy. In fact, $\overline{\mathrm{KE}_{\mathrm{IB}}}$ was barely elevated at NRL50S when the bore passed. For B2, $\overline{\mathrm{KE}_{\mathrm{IB}}}$ was greatest south of Point Sal and decreased toward the north. Notably, B2 had more $\overline{\mathrm{KE}_{\mathrm{IB}}}$ than B1 at VB50N and southward. At PS50, the $\mathrm{B} 1$ and $\mathrm{B} 2$ bores had comparable $\overline{\mathrm{KE}_{\mathrm{IB}}}$, and in the Oceano region $\mathrm{B} 1$ had more $\overline{\mathrm{KE}_{\mathrm{IB}}}$ than $\mathrm{B} 2$. The third bore, $\mathrm{B}$, had a more complicated alongshore pattern in KE, with the highest $\overline{\mathrm{KE}_{\mathrm{IB}}}$ values centered at Point Sal. At all locations except OC50, $\overline{\mathrm{KE}_{\mathrm{IB}}}$ increased prior to the $\mathrm{B} 3$ bore arrival so the duration of the $\overline{\mathrm{KE}_{\mathrm{IB}}}$ peak was longer. For $\mathrm{B} 4, \overline{\mathrm{KE}_{\mathrm{IB}}}$ was maximal south of the point at VB50S, and there was more energy in the 3 -min-1-h band relative to that of the previous bores. The alongshore variability of B4 is particularly evident in comparing OC50 and VB50S, as the magnitude of the $\overline{\mathrm{KE}_{\mathrm{IB}}}$ peak in the north was less than one-half that in the south.
The amount of energy in 3-min-16-h kinetic energy band also varied significantly from bore to bore (Figs. 6 and 8 ). There were times, such as the first peak on 10 September 2017 at NRL50S and VB50S (Fig. 6) and the B2 peak (Fig. 8), when there was little energy in the high frequency. Periods of relatively minimal high-frequency energy coincide with sharp bore fronts, as corroborated by the time series data at NRL50S when B2 arrived (Fig. 4). Other times, there was significant energy in the 3-min-1-h band (Figs. 6 and 8; difference between thin and thick lines), comparable to the kinetic energy in the 1-16-h band. For example, B4 had considerable energy in the high-frequency band near Point Sal (PS50-VB50S, Fig. 8).

\section{d. Comparing the cross-shore evolution of bores}

Based on the observation that alongshore bore continuity was dissimilar at the 50- and 25-m isobaths (Figs. 4 and 5) and that the subtidal shelf stratification varied alongshore (Fig. 2), our next step was to evaluate how upstream stratification conditions contribute to alongshore variability in a bore's cross-shore evolution. We compared two cross-shore transects from Oceano (Fig. 9) and Vandenberg (Fig. 10), focusing on the $\sim 36 \mathrm{~h}$ it took for the four consecutive bores to propagate from 100 to $10 \mathrm{~m}$. 


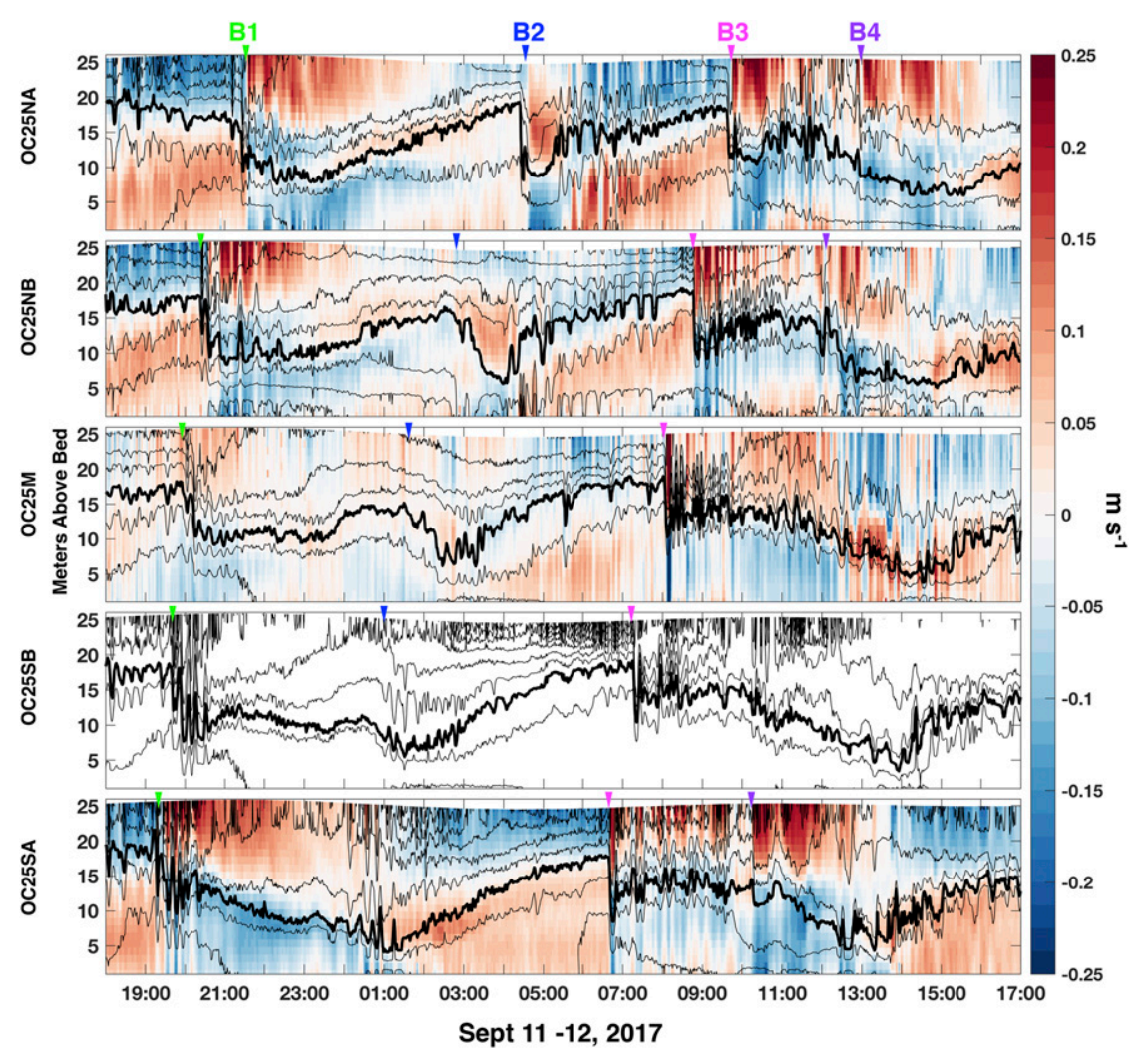

FIG. 5. As in Fig. 4, but for the 25 -m moorings north of Point Sal, each spaced $\sim 1 \mathrm{~km}$ apart along-coast. Note that these are the same four bores, B1-B4, as shown in Fig. 4, so the time period is adjusted to account for the time it took for the bores to travel the $\sim 5.3-\mathrm{km}$ distance from the $50-\mathrm{m}$ isobath to $25 \mathrm{~m}$.

At the northern transect (Fig. 9), B1 maintained a sharp frontal feature as it transited to $10-\mathrm{m}$ water depth. In contrast, B2 began to rarefy onshore of the 40-m isobath and became indistinct past $25 \mathrm{~m}$. We denote the possible remnants of the B2 by the white/blue triangles, but these did not pass the identification criteria and were weak signals compared to those offshore. Stratification ahead of B2 changed significantly across the shoaling region. Estimates of $\alpha$ were strongly positive at $50 \mathrm{~m}$ and weakened toward shore, becoming near zero at OC32S and negative at OC25SB (Fig. 9, subset). Qualitatively, B2's front gradually rarefied when the upstream $\alpha$ was near zero or negative (Fig. 9). The fate of B3 was similar to that of B1, but B4's fate was unique. At MS100 and OC50, the B3 and B4 bores were clearly separated. However, at OC40 and shoreward, the B4 front was impossible to distinguish from the back of B3.

There were both similar and contrasting bore evolution patterns at the southern cross-shore transect (Fig. 10). B1 and B3 similarly transited into a positive upstream $\alpha$ and maintained a sharp front to shore, but both had fewer highfrequency internal waves onshore of $50 \mathrm{~m}$ relative to their shape at the northern line. Unlike its fate in the north, B2 maintained a distinguishable pycnocline depression to shore but merged into the back of B1. In comparing the upstream surface current and the position of the $\mathrm{B} 2$ front relative to the
B1 front at OC50 (Fig. 9) and NRL50S (Fig. 10), it is evident at the $50-\mathrm{m}$ isobath that $\mathrm{B} 2$ already began merging into B1 at the $50-\mathrm{m}$ isobath in the southern part of the region. The alongshore difference in B2's evolution, especially relative to B1, is evident in a comparison of OC32S (Fig. 9) and NRL35S (Fig. 10). The time difference between B1 and B2 at OC32S was $\sim 5 \mathrm{~h}$, whereas it was only $\sim 2.5 \mathrm{~h}$ at NRL35S. Unlike its cross-shore evolution in the north, B4 had a distinguishable pycnocline depression that was trackable to the $20-\mathrm{m}$ isobath in the south (Fig. 10). Based on the narrowing window of time between the B3 and B4 arrivals from offshore to inshore, we posit that B4 merged into B3 shoreward of the NRL20S mooring.

The two cross sections (Figs. 9 and 10) qualitatively suggest that the upstream stratification influences a bore's evolution and fate while propagating into shallowing water. Bores maintained a sharp front when the upstream $\alpha$ was positive and rarefied when upstream $\alpha$ was near zero or negative, consistent with previous findings (Scotti et al. 2008; McSweeney et al. 2020).

\section{e. Bore sensitivity to alongshore-variable upstream stratification}

The comparisons of the 50-m moorings (Fig. 4) and the cross-shore transects (Figs. 9 and 10) corroborate that a bore's cross-shore evolution is sensitive to the upstream stratification, 

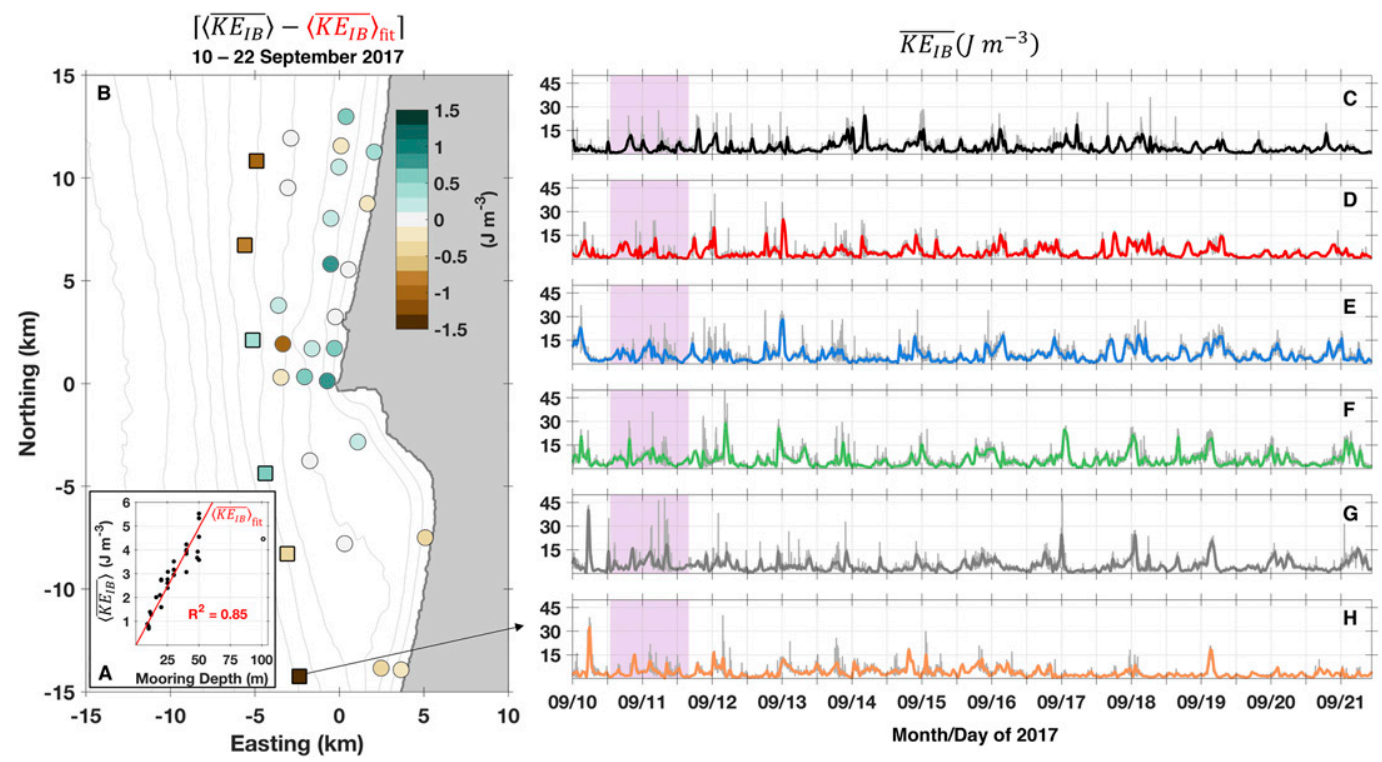

FIG. 6. (a) The depth-averaged internal bore (3-min-16-h bandpassed) kinetic energy averaged over 10-22 Sep 2017 (Fig. 2; gray) $\left(\left\langle\overline{\mathrm{KE}_{\mathrm{SD}}}\right\rangle ; \mathrm{J} \mathrm{m}^{-3}\right)$ as a function of mooring depth. Fit (excluding 100-m mooring; open dot) is shown in red. (b) Map of the $\left\langle\overline{\mathrm{KE}_{\mathrm{SD}}}\right\rangle$ anomaly relative to the isobath fit, $\left\langle\overline{\mathrm{KE}_{\mathrm{SD}}}\right\rangle_{\text {fit }}\left[\mathrm{J} \mathrm{m}^{-3}\right.$; shown in (a)]. (c)-(h) Also shown are time series of the depth-averaged kinetic energy $\left(\overline{\mathrm{KE}_{\mathrm{SD}}} ; \mathrm{J} \mathrm{m}^{-3}\right)$ for all of the 50 -m moorings [squares in (b)] from north in (c) to south in (h). The thick lines show the 1-16-h bandpassed KE, and the thin gray lines show the 3-min-16-h bandpassed KE. The colors of the thick lines correspond to those in Fig. 2.

but those analyses do not address how alongshore variability in the stratification influences a bore's alongshore coherency. To assess this, we considered the subtidal and 1-min $\alpha$ data at the 50-m moorings for the four bore passages (Fig. 11). Subtidal $\alpha$ was always positive, compared to the 1 -min $\alpha$ which often changed sign during a bore passage. The 1-min $\alpha$ provides insight about both how the upstream stratification affects a bore and how a bore effectively modifies local stratification. While the influence of internal bores on the local stratification appeared somewhat correlated at the 50-m moorings (Fig. 11), there are important discrepancies between the sites for the four bore cases that demonstrate that alongshore $\alpha$ gradients actually generate heterogeneity along a bore front.

For B1, the upstream $\alpha$ was strongly positive at every location but the bore's influence on the stratification varied alongshore. For example, at OC50 and NRL50S $\alpha$ was negative only briefly and the pycnocline quickly returned to a state where $\alpha$ was positive after the bore passage. In contrast, at VB50N and VB50S, the pycnocline remained depressed and $\alpha$ negative for hours. These differences in the pycnocline relaxation strongly affected the upstream $\alpha$ that B2 encountered. For instance, at NRL50S the upstream $\alpha$ was positive and the B2 passage sharply depressed the pycnocline. At VB50S, $\alpha$ ahead of B2 was near zero and after the pycnocline was depressed $\alpha$ remained negative for $\sim 2 \mathrm{~h}$. Farther north at NRL50N, the upstream $\alpha$ was positive but the B2 passage minimally affected the stratification. There were a few highfrequency fluctuations of $\alpha$, but the vertical structure of stratification was largely the same pre- and postbore passage.

Similar to B1, B3 had a positive upstream $\alpha$ at all the 50-m locations. However, B3 was more undular (Fig. 4) and had much more high-frequency energy (Fig. 8), which caused $\alpha$ to fluctuate for $30 \mathrm{~min}$ to $3.5 \mathrm{~h}$ depending on the alongshore location. The duration of these fluctuations was minimal near Point Sal and greatest to the north and south. After the passage of B3, $\alpha$ was nearly zero at every mooring. Transiting into a near-zero $\alpha$ that was mostly alongshore uniform, the fourth bore's passage surprisingly generated an alongshorevariable stratification response. At NRL50N, VB50S, and

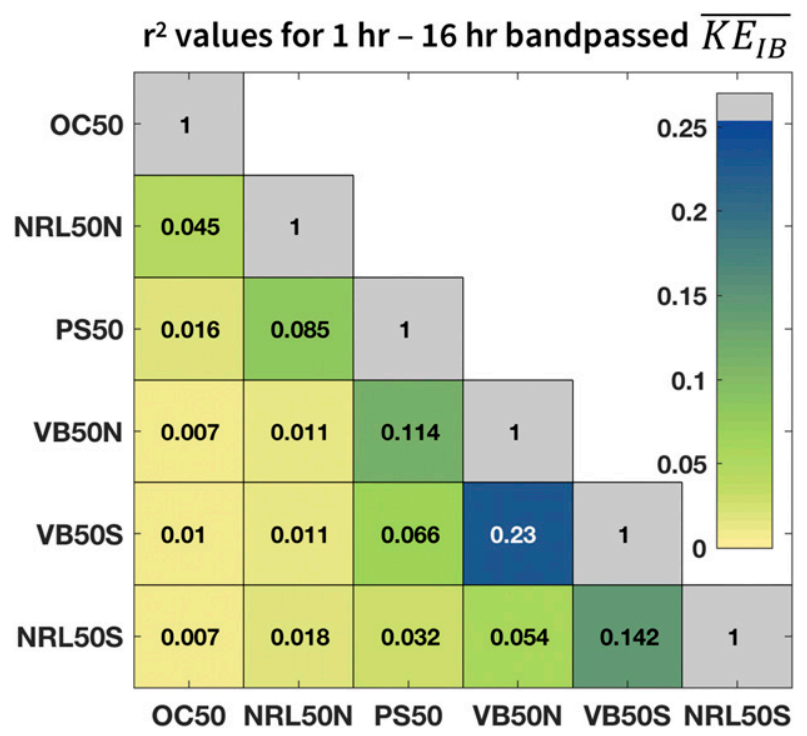

FIG. 7. Matrix of $r^{2}$ values for the 50-m mooring $\overline{\mathrm{KE}_{\mathrm{IB}}}$ time series from 10 Sep to 11 Oct. Correlations are calculated from the $1-16 \mathrm{~h}$ bandpassed velocities, such as shown in thick lines in Fig. 6. 


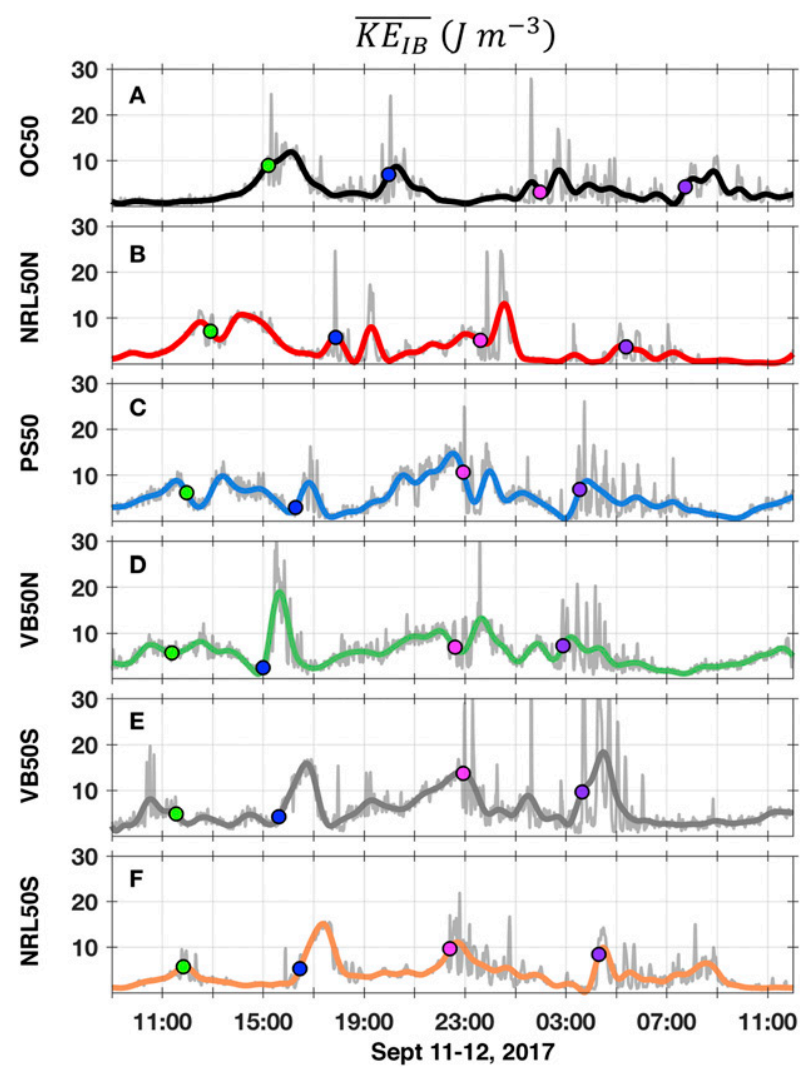

FIG. 8. As in Figs. 6c-h, but zoomed in on 11-12 Sep (pinkshaded time period in Fig. 6). Circles have been added to denote the B1-B4 bore arrivals.

NRL50S, $\alpha$ oscillated significantly immediately after B4 passed. The $\alpha$ oscillations were much more muted at the moorings between NRL50N and VB50S. There was a gradual increase in $\alpha$ after the $\mathrm{B} 4$ passage, but the magnitude and rate of increase varied alongshore.

These four bore cases provide insight into the complex ways internal bores both are influenced by and contribute to stratification variability. To further quantify bore-stratification feedbacks over the 2-month record, we evaluated the relationship between the prebore $\alpha$ and the change in $\alpha$ across the bore passage at all the 50 -m moorings $\left(\Delta \alpha=\alpha_{\text {pre }}-\alpha_{\text {post }}\right.$, Fig. 12). Similar to the calculation of $\alpha_{\text {pre }}$ [prebore $\alpha$; section $2 \mathrm{c}(1)], \alpha_{\text {post }}$ was calculated from the 30 -min-averaged density after a bore arrival. The prebore $\alpha$ and $\Delta \alpha$ were positively correlated with an $r^{2}$ value of 0.3 (Fig. 12), indicating that bores were larger in amplitude and had a stronger influence on stratification when the upstream $\alpha$ was a large, positive value. Since $\Delta \alpha$ represents the change in the vertical structure of stratification before and after a bore passage, $\Delta \alpha$ provides both a sense of how the internal bore modifies stratification and what the frontal shape of the bore is. A steep front would depress the pycnocline sharply and have a large $\Delta \alpha$ value, where as a rarefied front would have a smaller $\Delta \alpha$ value and a lesser impact on stratification. The correlation between prebore $\alpha$ and $\Delta \alpha$ indicates that the upstream stratification modulated the influence of internal bores on shelf stratification but that other factors were also influential.

Similar analyses were done using other metrics of stratification, but were less insightful. The key here is that the vertical structure of the water column (not just the "strength" of stratification) modulated and was modulated by passing internal waves, which we quantified using $\alpha$.

\section{f. Mapping bore propagation across shore}

Spatial maps of the shoreward-propagating, sequential bores and hourly $\alpha$ averages for each hour from 1100 UTC 11 September to 060012 September 2017 (Fig. 13) aid in visualizing the impact of internal bores on regional stratification variability. The hourly $\alpha$ values are $1 \mathrm{~h}$, centered averages of the 1 -min $\alpha$ data at every mooring. For example, the data at 1100 UTC (Fig. 13a) are an average of the 1-min $\alpha$ data from 1030 to 1130 UTC. During this 15 -h timespan, the bores B1-B4 transited through the mooring array, as well as the bore (black) preceding B1 (green), which was finishing its transit through the Oceano region.

We detail B1's transit to highlight the feedbacks between $\alpha$ and the bore propagation. At 1100 UTC 11 September 2017, $\alpha$ was positive along the $50-\mathrm{m}$ isobath, just ahead of B1, with the smallest values offshore of Point Sal. An hour later, B1 had passed VB50N/S and depressed the pycnocline at these locations (negative $\alpha$ ). At 1500 UTC 11 September 2017, the bore had passed NRL50N and the 40-35 m moorings near Point Sal, leaving $\alpha$ negative in its wake. The $\alpha$ values at VB50N/S had begun to increase in value as the bore moved farther inshore. As B1 continued to shoal, there was a consistent pattern of $\alpha$ being positive upstream and negative downstream of the bore. Bore B1 reached shore at Point Sal at $\sim 1900$ UTC, in the south at $\sim 2000$ UTC, and in the north at $\sim 2200$ UTC.

Across the broader region, B2 (blue) propagated into negative $\alpha$ that was strongly impacted by B1's passage. The map of $\alpha$ (Figs. 13h,i) illustrates that $\alpha$ was negative ahead of B2 onshore of the 50-m isobath at every cross section except for the southernmost, which is valuable context for considering the prebore $\alpha$ from the cross-shore transects (Figs. 9 and 10). The hourly maps offer a broader perspective, with which to see how a shoaling bore evolved differently at different alongshore locations. On 11 September 2017 at 1900 UTC, B2 disappeared south of Point Sal, the front became discontinuous alongshore (Fig. 13). The development of discontinuity of B2 is consistent with observations that length scales of alongshore bore continuity are shorter nearshore (Figs. 4 and 5). B2 propagated toward shore from the southwest at a similar angle as B1, with the distance between the 2 bores significantly shorter south of Point Sal. This corroborates that B2 was likely merging into the back end of B1 near and to the south of the headland.

While the in situ data from cross-shore transects (Figs. 9 and 10) suggested similarities between B1 (green) and B3 (pink), the maps provide supporting evidence that their resemblances extend beyond the two transect locations (Fig. 13). Comparing the bore positions 1500 UTC 11 September and 0100 UTC 12 September 2017, we observe that the stratification upstream and downstream from the bores was similar. The preceding bores (black and blue, respectively) were also 


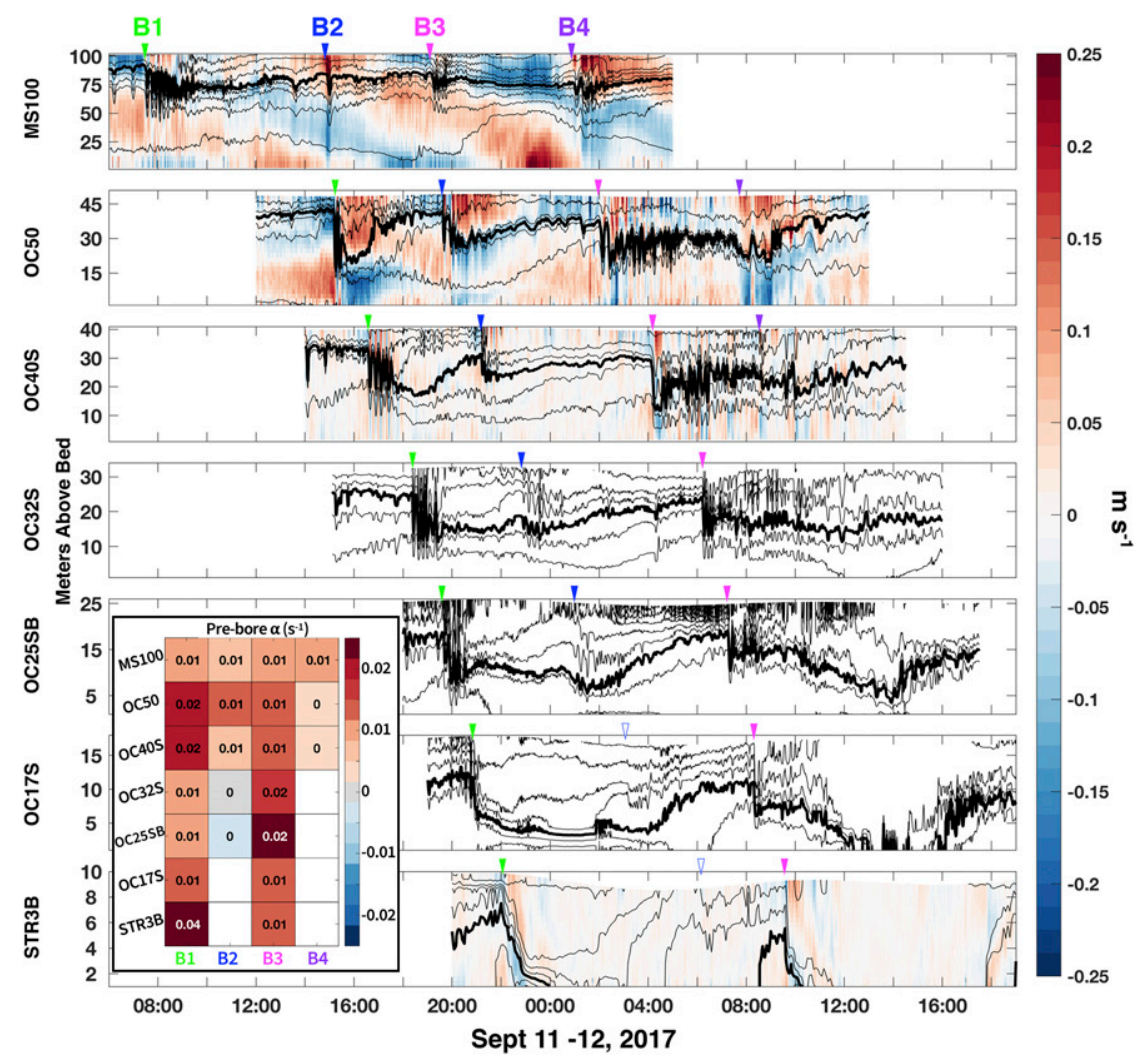

FIG. 9. The 16-h high-pass-filtered baroclinic eastward velocity $\left(\mathrm{m} \mathrm{s}^{-1}\right.$; colored, with positive values toward east) and 1 -min temperature $\left({ }^{\circ} \mathrm{C}\right.$; black contours at $1^{\circ}$ intervals, with the $15^{\circ}$ isotherm thicker) for MS100, OC50, OC40S, OC32S, OC25SB, OC17S, and STR3B (from offshore at the top of the figure to onshore at the bottom) from 0600 UTC 11 Sep to 1900 UTC 12 Sep 2017. The $y$ axis is meters above the bed. The subset figure shows the prebore $\alpha$ ahead of each bore, where white denotes that a bore was not identifiable. Bores B1-B4 are noted by the filled triangles. The white/blue triangles in the bottom panels were added as a visual aid for our discussion, but, unlike the filled triangles, they were not identified as bore arrivals by the identification criteria.

similarly positioned, but had a different upstream stratification. The $\alpha$ maps demonstrate that the region has rich spatiotemporal variability in stratification, which is evolving within the period it takes a bore to transit across the shelf.

To verify whether the mapped bore positions (Fig. 13) capture realistic alongshore structure, we compared a mapped bore with available land-based X-band radar data from 19 September 2017 (Fig. 14). The bore was visible from the bright banding in the radar data and had a consistent frontal feature that spanned the $\sim 35-\mathrm{km}$ observational range (Fig. 14a). From a series of snapshots separated by $1.5 \mathrm{~h}$, we observe that the two data products agreed remarkably well and that the mapped bore front captured realistic changes in the alongshore frontal position over the $3 \mathrm{~h}$ period. There are sometimes small offsets between the frontal position from the radar and in situ data, which may be real for a myriad of reasons, such as a bore changing speed across shore. However, these spatiotemporal offsets are relatively minor and the elucidation of their cause is beyond the scope of this paper. Overall, the agreement between the radar data and the mapped bore positions provides confidence in our approach and findings (Fig. 13).

\section{Discussion}

\section{a. Bore fates during shoaling}

We observed three bore fates during shoaling: 1) bores transiting intact to shore, 2) bores merging into the back of the previous bore and 3 ) bores becoming indistinct in the case of a negative upstream $\alpha$. A single bore that is continuous at the $50-\mathrm{m}$ isobath can experience different fates alongshore, depending on the alongshore variability of the upstream stratification it encounters. For example, the B2 bore disappeared beyond the 25-m isobath both north (Fig. 9) and south (Fig. 13) of Point Sal, but it propagated all the way to shore at the southernmost transect and began to merge into B1 (Figs. 10 and 13). The B4 bore appeared to merge into the back of B3 and became indistinct at all alongshore cross sections, but the cross-shelf location of its disappearance varied alongshore (Figs. 9 and 10). 


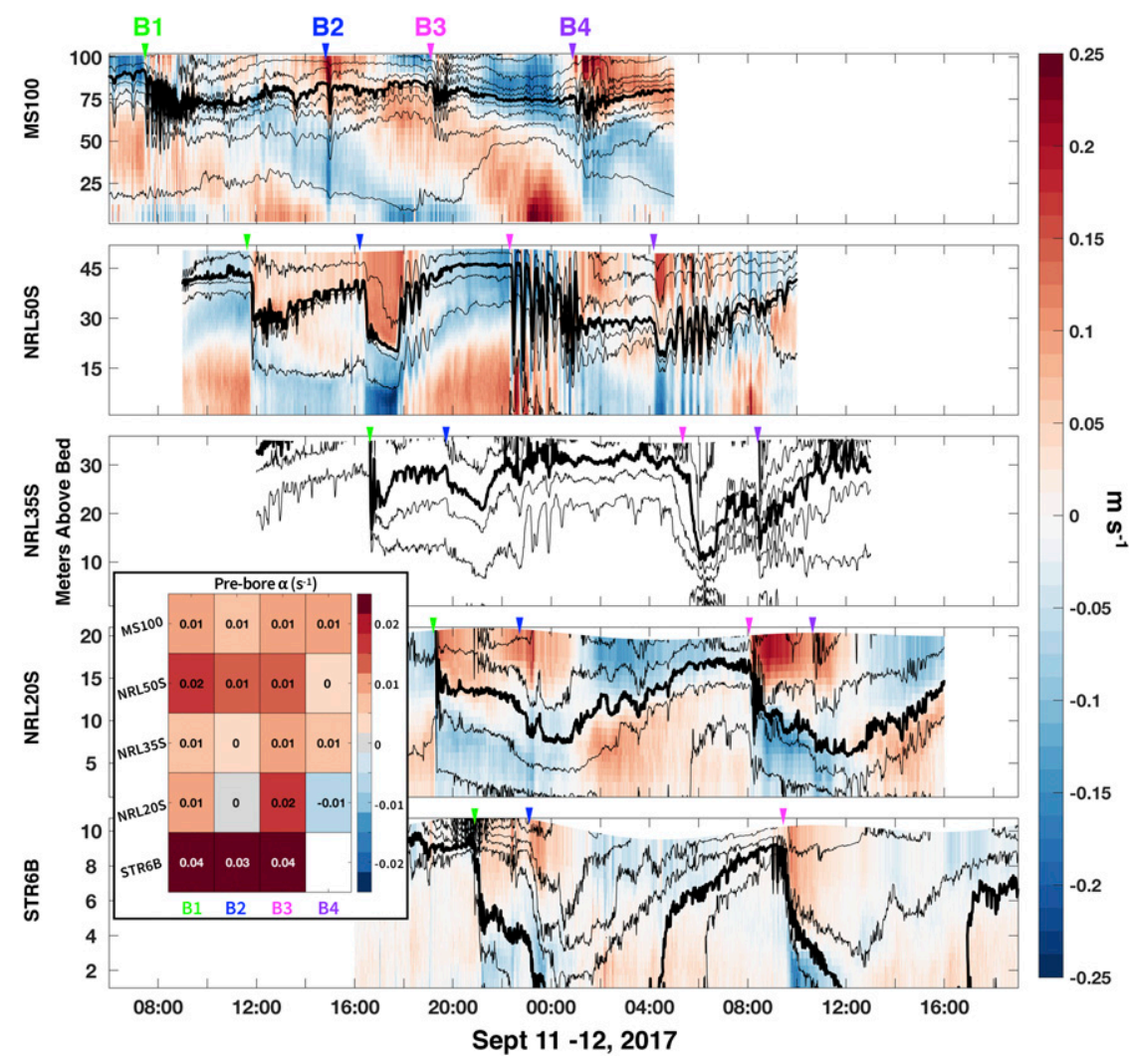

FIG. 10. As in Fig. 9, but for moorings MS100, NRL50S, NRL35S, NRL20S, and STR6B-the southernmost cross-shore mooring transect.

We observed that the length scales of alongshore bore continuity decreased from the 50-m isobath (Fig. 4) to the $25-\mathrm{m}$ isobath (Fig. 5). We explained the decreasing length scales of coherence through an event-scale analysis of the alongshore variability of a bore's cross-shore evolution (Figs. 9 and 10). While this analysis focused on the dynamics of four bore events, it is important to remember that the evolution of internal waves is also modulated by subtidal changes in stratification variability (McSweeney et al. 2020). Given the myriad of subtidal processes that are influencing shelf properties, further work is needed to diagnose whether our findings are representative of alongshore bore continuity over a longer time scale.

The mechanisms that contribute to the dissipation of the internal bores during their cross-shore transformation has been an active research topic (Henyey and Hoering 1997; Moum et al. 2003, 2007a,b; Walter et al. 2014; Becherer et al. 2020), and our observations suggest that the three-dimensional nature of internal tides during shoaling may contribute to the spatial and temporal patterns of internal bore destruction. Jointly, the cross sections of shoaling bores (Figs. 9 and 10) and the maps of bore loss near Point Sal (Fig. 13), could support the conclusion of Vlasenko and Stashchuk (2007) that elevated levels of mixing and turbulence by internal waves are expected near headlands where horizontal wave refraction can generate concavity along bore fronts. Our analysis neither confirms frontal concavity nor provides an analysis of turbulence data, but it does suggest that bores frequently merge or disappear near the headland. Bores merging/disappearing near the Point Sal headland could imply a local increase of kinetic energy associated with internal waves, which would be consistent with the alongshore patterns of semidiurnal energy derived from statistical analyses of nearshore mooring data (Feddersen et al. 2020). As internal bores have rich alongshore structure that is always evolving, a follow up analysis to quantify the internal bore influences on patterns of shelf turbulence and dissipation would be valuable.

\section{b. Detangling feedbacks between shelf stratification variability and internal bores}

Teasing apart the feedback between shelf stratification variability and shoaling internal waves is not trivial. We demonstrated here that shoaling internal bores were influenced by the vertical structure of the upstream stratification and also contributed to shelf stratification variability. Expanding on the finding that the cross-shelf evolution of internal bores is qualitatively different under varying $\alpha$ conditions (McSweeney et al. 2020), we demonstrated that alongshore gradients in $\alpha$ effectively generate heterogeneity along an internal bore front. Conversely, an internal bore can also generate alongshore variability of stratification if the frontal structure significantly differs alongshore. For example, the upstream stratification ahead of the B1 bore was relatively alongshore-uniform at the 

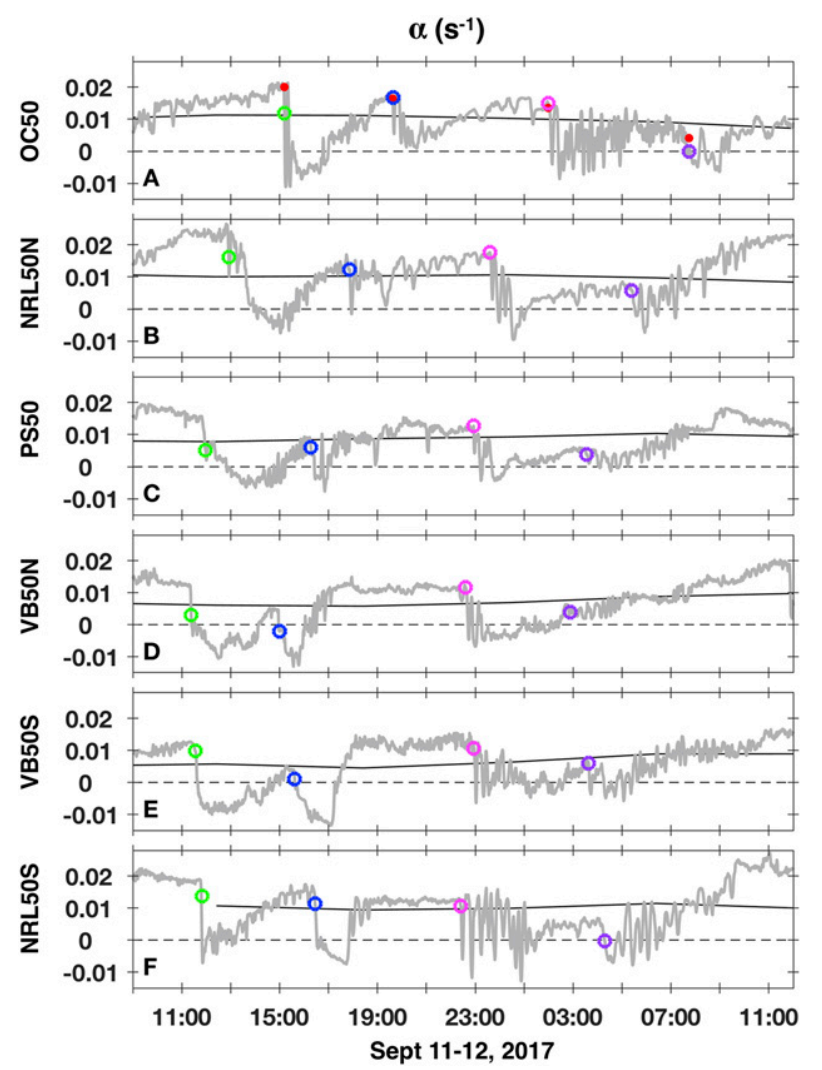

FIG. 11. The $\alpha\left(\mathrm{s}^{-1}\right)$ estimated from the subtidal (black line) and 1-min density data (gray line) for the 50-m moorings. Colored circles denote the B1-B4 bore arrivals (as in Fig. 8). For OC50, the prebore (red dots) $\alpha$ values are also shown (corresponding to the colored dots in Fig. 3).

50-m isobath, but the stratification there became alongshore heterogenous after the bore passage (Fig. 11). We speculate that the creation of this alongshore stratification variability was caused by alongshore variability in the bore's structure (Fig. 4) and energy (Fig. 8).

There has been a lot of progress in understanding how upstream stratification variability affects a shoaling bore's evolution (Vlasenko and Hutter 2002; Stastna and Lamb 2002; Scotti et al. 2008; McSweeney et al. 2020), but there are still many open questions about the influence of shoaling internal waves on shelf stratification (e.g., Moum et al. 2003; MacKinnon and Gregg 2003a; Scotti et al. 2007, 2008; Walter et al. 2012). As internal waves propagate to shore, they generate instabilities and turbulent mixing that have a nonadiabatic effect on local stratification (Moum et al. 2003). A single bore can substantially modify local mixing, with the bore's leading and trailing edge contributing differently to the mixing dynamics (Walter et al. 2014). Our understanding of how internal waves effectively influence local stratification has mostly been rooted in a 2D crossshore framework, but we demonstrate that internal bores have important alongshore variability and can contribute to horizontal variability of stratification on shelf scales (Figs. 11 and 13).

While the influence of internal waves on shelf stratification is evident (Fig. 14), additional analysis would be necessary to

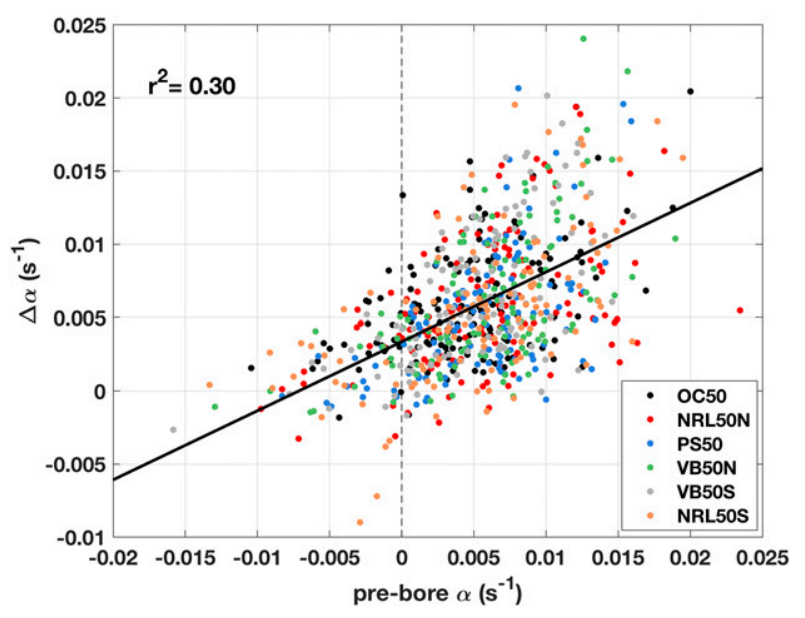

FIG. 12. At the six 50-m moorings, the prebore $\alpha$ vs $\Delta \alpha$, the change in $\alpha$ across the bore; $\Delta \alpha$ is calculated by taking the difference between $\alpha$ averaged over the $30 \mathrm{~min}$ before and after the bore. The linear regression (black line) and correlation coefficient $\left(r^{2}\right)$ are also shown.

evaluate its relative contribution compared to that of other inner shelf processes. The comparison of the subtidal and 1-min $\alpha$ (Fig. 3c) along with the bore positions relative to horizontal $\alpha$ patterns (Fig. 13) demonstrated that the modification of local stratification by internal tides may be more important than subtidal modulation for the regional patterns of stratification variability on short time scales ( $<1$ week). In contrast, we observed that subtidal modulation of the relative strength of stratification $\left(c_{o}\right.$ and $\left.\Delta T\right)$ dominates internal wave influences at the $50-\mathrm{m}$ moorings (Figs. 3a,b). These findings imply that the modulation of shelf stratification by subtidal and internal wave processes is distinctly different, but the relative importance of each is challenging to diagnose.

\section{c. Kinetic energy variability along an internal tidal bore}

We observed that the semidiurnal kinetic energy varies significantly along internal bore fronts, with unique alongshore patterns of variability for each bore (Figs. 6 and 8). There were no obvious patterns in the bore-to-bore alongshore KE gradients, but a 2-week average yielded a pattern of maximal KE at Point Sal that decreased both to the north and south. These findings were similar to observations from Massachusetts Bay of bore-to-bore variability in the alongshore patterns of highfrequency internal wave KE (Thomas et al. 2016). However, while only 3 of the 12 of the Massachusetts Bay bores had notable alongshore KE variability (Thomas et al. 2016, their Fig. 9), the along-bore KE gradient was significant for most bores in our study. Bore-to-bore variability in $\mathrm{KE}$ is not a new observation (MacKinnon and Gregg 2003b), but our finding that along-bore $\mathrm{KE}$ gradients vary from bore to bore is novel.

A comparison of KE time series with different bandpass filters (Figs. 6 and 8) revealed that the high-frequency (periods $<1 \mathrm{~h}$ ) energy content can be comparable to or even exceed the energy in the 1-16-h band. The bore structures (Fig. 4) and KE time series (Fig. 8) we observed are consistent with previous suggestions that semidiurnal energy can be transferred to higher frequencies through the evolution of a bore and its higher-frequency 

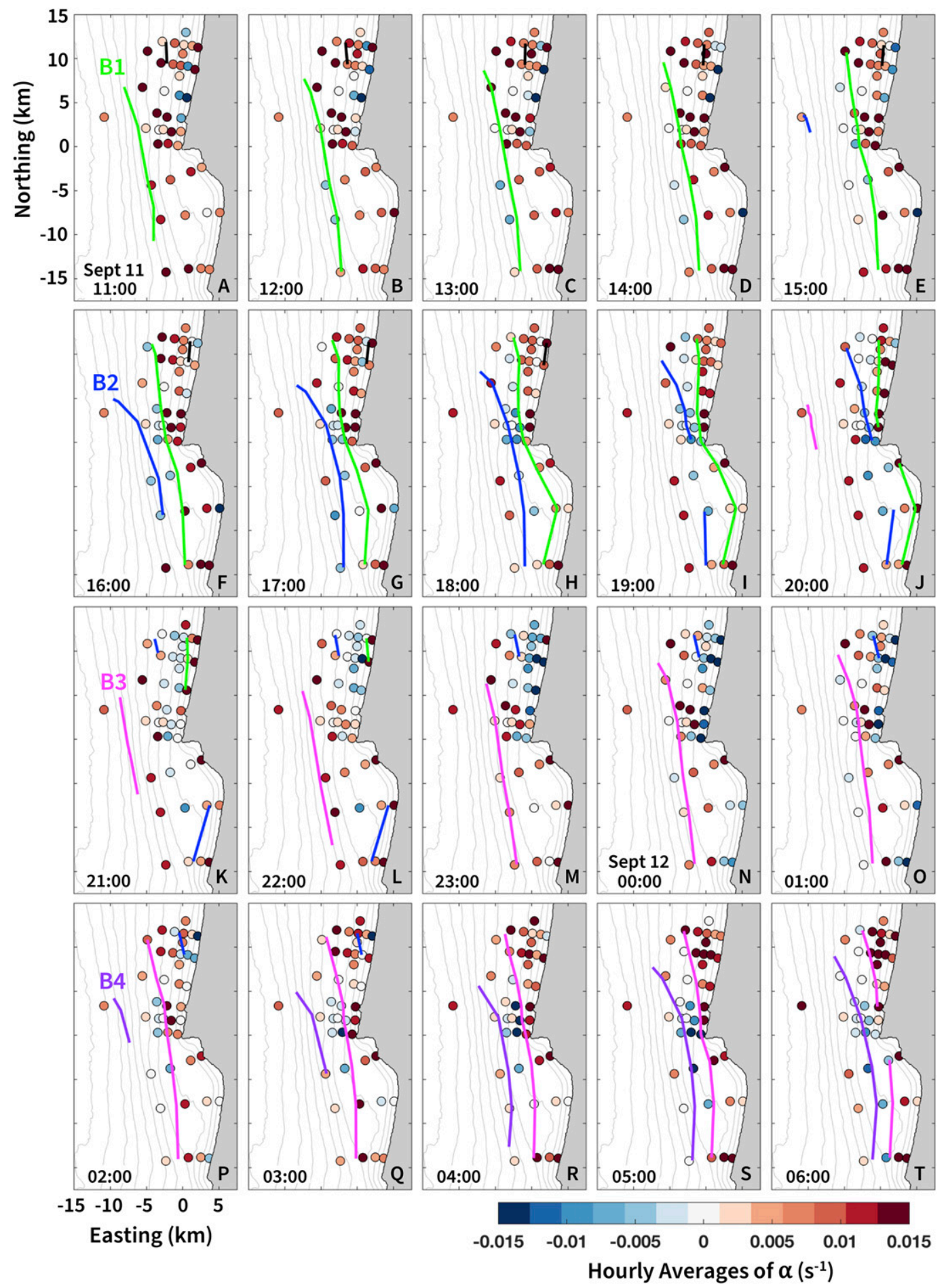

FIG. 13. Maps of hourly-averaged $\alpha$ (colored dots) estimated from the 1-min density data (Fig. 3; gray line), shown at 1-h intervals, with time increasing from (a) to (t). The colored line shows the mapped position of B1-B4 bores each hour. The colors of the bore correspond to those used in other figures, with the addition of the B0 (black) bore ahead of B1 (green). The bore position is determined by interpolating bore arrival times at each mooring across the nine cross-shore transects shown in Fig. 1. 


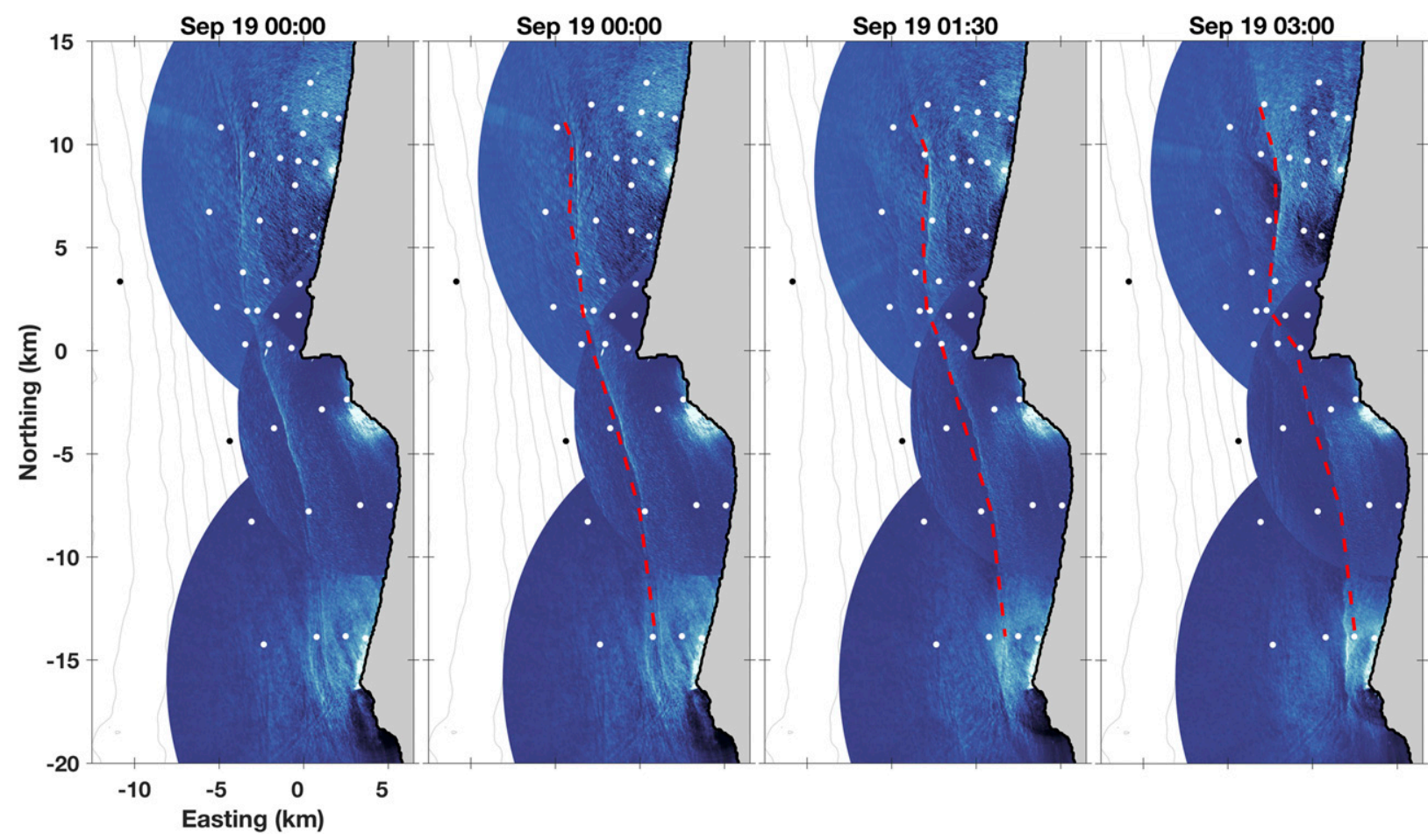

FIG. 14. Composite X-band radar from three land-based stations (colored) on 19 Sep 2017 at (a),(b) 0000, (c) 0130, and (d) 0300 UTC. The mooring locations are denoted by white or black circles, and the red dashed line in (b)-(d) indicate the mapped bore location based on the in situ data alone (as shown in Fig. 13).

internal waves (Holloway et al. 1997; MacKinnon and Gregg 2003b). The energy distribution between the semidiurnal and high-frequency bands may also vary along a front (Fig. 8), which could imply that internal waves may redistribute energy both in the along- and across-shelf directions.

We discussed the alongshore variability of KE on event and week-long time scales, but we must also consider these gradients can vary on longer time scales. Over the 2-month observational period, the semidiurnal $\mathrm{KE}$ at the $50-\mathrm{m}$ isobath tended to be greater near Point Sal than in the Oceano and Vandenberg regions (Fig. 2). Further work is needed to diagnose the lowfrequency and longer-term variability of KE spatial heterogeneity.

We have qualitatively described the locations of bore destruction (section 4a) and quantified the alongshore gradients in KE through time averages (Fig. 7) and at an event scale (Fig. 9), but further work is needed to relate the spatiotemporal $\mathrm{KE}$ variability to mixing and dissipation processes. Extensive turbulence measurements were collected in the Inner Shelf Dynamics Experiment, and ongoing research efforts focus on the impact of internal wave variability on patterns of energy loss and mixing (Becherer et al. 2020). Given the productivity within the region and the prominence of upwelling dynamics, the influence of internal waves on spatiotemporal patterns of KE likely has important ecosystem impacts (Woodson 2018).

\section{Conclusions}

Inner-shelf stratification variability in both the alongshore and cross-shelf directions was modulated by subtidal and high-frequency processes. This analysis demonstrated that internal bores are both influenced by and contribute to the stratification variability. For example, the vertical structure of stratification (measured by $\alpha$ ) upstream of a bore strongly influenced whether a bore maintained a sharp front or rarefied. Furthermore, $\alpha$ ahead of a bore was positively correlated to the change in $\alpha$ across the bore. Alongshore gradients in $\alpha$ played a key role in introducing along-bore heterogeneity to shoaling bores. With internal bores transiting through the region every $\sim 6 \mathrm{~h}$ (McSweeney et al. 2020), there were often two or three bores simultaneously influencing the local stratification and contributing to broader spatiotemporal variability of stratification.

From a comparison of in situ mooring data at the 50- and $25-\mathrm{m}$ isobaths, we found that the length scales of alongshore internal bore continuity decreased toward shore. We observed bore fronts to be continuous for tens of kilometers at the 50-m isobath, but at $25 \mathrm{~m}$ their continuity length scales were on the order of a few kilometers. Spatial maps of propagating bores corroborated the conclusion that length scales of bore continuity are greater offshore.

Although the majority of bores had an alongshorecontinuous front, each bores' semidiurnal kinetic energy was alongshore nonuniform. A correlation analysis of the $\mathrm{KE}$ time series at the 50-m moorings confirmed that KE was decorrelated alongshore. Furthermore, the time series revealed bore-to-bore variability in the alongshore KE gradients. A map of the KE averaged over a 2-week period 
indicated that KE was highest around Point Sal when compared with sites northward and southward.

Through a comparison of different cross-shore transects and hourly maps of $\alpha$ and bore position, we tracked four sequential bores as they transited to shore. The alongshore variability of stratification, driven by both subtidal process and the internal tides themselves, can introduce alongshore variability to a bore's cross-shore evolution. We observe three bore fates within our dataset. A bore can 1) transit all the way to shore (9$10 \mathrm{~m}$ in our case), 2) merge into the back of the previous bore, or 3) become indistinguishable due to rarefication. Depending on the alongshore variability of the upstream stratification, a single bore may have various fates at different along-coast locations. This analysis, to our knowledge, is the first dataset to demonstrate that a bore with an alongshore-continuous front at midshelf can develop alongshore variability in the frontal feature due to a heterogenous waveguide.

While most studies consider only the two-dimensional dynamics of internal waves, these findings demonstrated that the cross-shore evolution of shoaling internal bores is inherently complex and three-dimensional. The alongshore variability of internal bores is likely a significant influence on patterns of cross-shelf transport, mixing, and shelf stratification.

Acknowledgments. We thank everyone involved in the data collection and processing, as well as two anonymous reviewers who provided helpful suggestions for revising the paper. Funding was provided by the Office of Naval Research. Data on the project-scale are archived at UC San Diego Library Digital Collections (https://doi.org/10.6075/J0WD3Z3Q).

\section{REFERENCES}

Alford, M. H., R.-C. Lien, H. Simmons, J. Klymak, S. Ramp, Y. J. Yang, D. Tang, and M.-H. Chang, 2010: Speed and evolution of nonlinear internal waves transiting the South China Sea. J. Phys. Oceanogr., 40, 1338-1355, https://doi.org/10.1175/ 2010JPO4388.1.

Aristizábal, M. F., M. R. Fewings, and L. Washburn, 2016: Contrasting spatial patterns in the diurnal and semidiurnal temperature variability in the Santa Barbara Channel, California. J. Geophys. Res. Oceans, 121, 427-440, https://doi.org/10.1002/2015JC011239.

Badiey, M., L. Wan, and A. Song, 2013: Three-dimensional mapping of evolving internal waves during the Shallow Water 2006 experiment. J. Acoust. Soc. Amer., 133, 3345, https://doi.org/ 10.1121/1.4805661.

Becherer, J., J. N. Moum, J. A. Colosi, J. A. Lerczak, and J. M. McSweeney, 2020: Turbulence asymmetries in bottom boundary layer velocity pulses associated with onshore-propagating nonlinear internal waves. J. Phys. Oceanogr., 50, 2373-2391, https://doi.org/10.1175/JPO-D-19-0178.1.

Buijsman, M. C., Y. Uchiyama, J. C. McWilliams, and C. R. HillLindsay, 2012: Modeling semidiurnal internal tide variability in the Southern California Bight. J. Phys. Oceanogr., 42, 6277, https://doi.org/10.1175/2011JPO4597.1.

Butman, B., P. S. Alexander, A. Scotti, R. C. Beardsley, and S. P. Anderson, 2006: Large internal waves in Massachusetts Bay transport sediments offshore. Cont. Shelf Res., 26, 2029-2049, https://doi.org/10.1016/j.csr.2006.07.022.

Colosi, J. A., N. Kumar, S. H. Suanda, T. M. Freismuth, and J. H. MacMahan, 2018: Statistics of internal tide bores and internal solitary waves observed on the inner continental shelf off Point Sal, California. J. Phys. Oceanogr., 48, 123-143, https:// doi.org/10.1175/JPO-D-17-0045.1.

Cudaback, C. N., and E. McPhee-Shaw, 2009: Diurnal-period internal waves near point conception, California. Estuarine Coastal Shelf Sci., 83, 349-359, https://doi.org/10.1016/j.ecss.2008.12.018.

Duda, T. F., J. M. Collis, Y.-T. Lin, A. E. Newhall, J. F. Lynch, and H. A. DeFerrari, 2012: Horizontal coherence of low-frequency fixed-path sound in a continental shelf region with internalwave activity. J. Acoust. Soc. Amer., 131, 1782-1797, https:// doi.org/10.1121/1.3666003.

Edwards, C. R., and H. E. Seim, 2008: Complex EOF analysis as a method to separate barotropic and baroclinic velocity structure in shallow water. J. Atmos. Oceanic Technol., 25, 808-821, https://doi.org/10.1175/2007JTECHO562.1.

Feddersen, F., J. H. MacMahan, T. M. Freismuth, M. K. Gough, and M. Kovatch, 2020: Inner-shelf vertical and alongshore temperature variability in the subtidal, diurnal, and semidiurnal bands along the central California coastline with headlands. J. Geophys. Res. Oceans, 125, e2019JC015347, https:// doi.org/10.1029/2019JC015347.

Garrett, C., and E. Kunze, 2007: Internal tide generation in the deep ocean. Annu. Rev. Fluid Mech., 39, 57-87, https://doi.org/ 10.1146/annurev.fluid.39.050905.110227.

Grimshaw, R., and K. Helfrich, 2012: The effect of rotation on internal solitary waves. IMA J. Appl. Math., 77, 326-339, https://doi.org/10.1093/imamat/hxs024.

— E. Pelinovsky, and T. Talipova, 1997: The modified Korteweg-de Vries equation in the theory of large-amplitude internal waves. Nonlinear Processes Geophys., 4, 237-250, https://doi.org/10.5194/ npg-4-237-1997.

- — , and O. Poloukhina, 2002: Higher-order Korteweg-de Vries models for internal solitary waves in a stratified shear flow with a free surface. Nonlinear Processes Geophys., 9, 221-235, https://doi.org/10.5194/npg-9-221-2002.

—, C. Guo, K. Helfrich, and V. Vlasenko, 2014: Combined effect of rotation and topography on shoaling oceanic internal solitary waves. J. Phys. Oceanogr., 44, 1116-1132, https://doi.org/ 10.1175/JPO-D-13-0194.1.

Helfrich, K. R., and W. K. Melville, 1986: On long nonlinear internal waves over slope-shelf topography. J. Fluid Mech., 167, 285-308, https://doi.org/10.1017/S0022112086002823.

Henyey, F. S., and A. Hoering, 1997: Energetics of borelike internal waves. J. Geophys. Res., 102, 3323-3330, https://doi.org/ 10.1029/96JC03558.

Holloway, P. E., E. Pelinovsky, T. Talipova, and B. Barnes, 1997: A nonlinear model of internal tide transformation on the Australian North West Shelf. J. Phys. Oceanogr., 27, 871-896, https://doi.org/ 10.1175/1520-0485(1997)027<0871:ANMOIT>2.0.CO;2.

Kumar, N., S. H. Suanda, J. A. Colosi, K. Haas, E. Di Lorenzo, A. J. Miller, and C. A. Edwards, 2019: Coastal semidiurnal internal tidal incoherence in the Santa Maria Basin, California: Observations and model simulations. J. Geophys. Res. Oceans, 124, 5158-5179, https://doi.org/10.1029/2018JC014891.

Lee, C., and R. C. Beardsley, 1974: The generation of long nonlinear internal waves in a weakly stratified shear flow. J. Geophys. Res., 79, 453-462, https://doi.org/10.1029/ JC079i003p00453.

Lentz, S. J., and M. R. Fewings, 2012: The wind-and wave-driven inner-shelf circulation. Annu. Rev. Mar. Sci., 4, 317-343, https://doi.org/10.1146/annurev-marine-120709-142745.

Lerczak, J. A., C. D. Winant, and M. C. Hendershott, 2003: Observations of the semidiurnal internal tide on the southern 
California slope and shelf. J. Geophys. Res., 108, 3068, https:// doi.org/10.1029/2001JC001128.

— surf meets coastal ocean. Eos, Trans. Amer. Geophys. Union, 100, https://doi.org/10.1029/2019EO122141.

Lin, Y.-T., A. E. Newhall, and J. F. Lynch, 2012: Low-frequency broadband sound source localization using an adaptive normal mode back-propagation approach in a shallow-water ocean. J. Acoust. Soc. Amer., 131, 1798-1813, https://doi.org/10.1121/ 1.3672643 .

- K. G. McMahon, J. F. Lynch, and W. L. Siegmann, 2013: Horizontal ducting of sound by curved nonlinear internal gravity waves in the continental shelf areas. J. Acoust. Soc. Amer., 133, 37-49, https://doi.org/10.1121/1.4770240.

MacKinnon, J. A., and M. C. Gregg, 2003a: Mixing on the latesummer New England shelf-Solibores, shear, and stratification. J. Phys. Oceanogr., 33, 1476-1492, https://doi.org/ 10.1175/1520-0485(2003)033<1476:MOTLNE > 2.0.CO;2.

- , and — 2003b: Shear and baroclinic energy flux on the summer New England shelf. J. Phys. Oceanogr., 33, 1462-1475, https://doi.org/10.1175/1520-0485(2003)033<1462: $\mathrm{SABEFO}>2.0 . \mathrm{CO} ; 2$.

McSweeney, J. M., and Coauthors, 2020: Observations of shoaling nonlinear internal bores across the central California inner shelf. J. Phys. Oceanogr., 50, 111-132, https://doi.org/10.1175/ JPO-D-19-0125.1.

Moum, J. N., D. M. Farmer, W. D. Smyth, L. Armi, and S. Vagle, 2003: Structure and generation of turbulence at interfaces strained by internal solitary waves propagating shoreward over the continental shelf. J. Phys. Oceanogr., 33, 2093-2112, https://doi.org/ 10.1175/1520-0485(2003)033<2093:SAGOTA > 2.0.CO;2.

- _ - E. L. Shroyer, W. D. Smyth, and L. Armi, 2007a: Dissipative losses in nonlinear internal waves propagating across the continental shelf. J. Phys. Oceanogr., 37, 1989-1995, https://doi.org/10.1175/JPO3091.1.

— J. M. Klymak, J. D. Nash, A. Perlin, and W. D. Smyth, 2007b: Energy transport by nonlinear internal waves. J. Phys. Oceanogr., 37, 1968-1988, https://doi.org/10.1175/JPO3094.1.

Ostrovsky, L. A., and K. R. Helfrich, 2019: Some new aspects of the joint effect of rotation and topography on internal solitary waves. J. Phys. Oceanogr., 49, 1639-1649, https://doi.org/ 10.1175/JPO-D-18-0154.1.

Ramp, S. R., and Coauthors, 2004: Internal solitons in the northeastern South China Sea Part I: Sources and deep water propagation. IEEE J. Oceanic Eng., 29, 1157-1181, https:// doi.org/10.1109/JOE.2004.840839.

Regal, R., and C. Wunsch, 1973: $M_{2}$ tidal currents in the western North Atlantic. Deep-Sea Res. Oceanogr. Abstr., 20, 493-502, https://doi.org/10.1016/0011-7471(73)90102-2.
Scotti, A., R. C. Beardsley, and B. Butman, 2007: Generation and propagation of nonlinear internal waves in Massachusetts Bay. J. Geophys. Res., 112, C10001, https://doi.org/10.1029/ 2007JC004313.

,,$---\frac{1}{-}$ and J. Pineda, 2008: Shoaling of nonlinear internal waves in Massachusetts Bay. J. Geophys. Res., 113, C08031, https://doi.org/10.1029/2008JC004726.

Shroyer, E. L., J. N. Moum, and J. D. Nash, 2011: Nonlinear internal waves over New Jersey's continental shelf. J. Geophys. Res., 116, C03022, https://doi.org/10.1029/2010JC006332.

Stastna, M., and K. G. Lamb, 2002: Large fully nonlinear internal solitary waves: The effect of background current. Phys. Fluids, 14, 2987-2999, https://doi.org/10.1063/1.1496510.

Tang, D., and Coauthors, 2007: Shallow Water'06: A joint acoustic propagation/nonlinear internal wave physics experiment. Oceanography, 20,156-167, https://doi.org/10.5670/ oceanog.2007.16.

Thomas, J. A., J. A. Lerczak, and J. N. Moum, 2016: Horizontal variability of high-frequency nonlinear internal waves in Massachusetts Bay detected by an array of seafloor pressure sensors. J. Geophys. Res. Oceans, 121, 5587-5607, https:// doi.org/10.1002/2016JC011866.

Vlasenko, V., and K. Hutter, 2002: Numerical experiments on the breaking of solitary internal wavesover a slope-shelf topography. J. Phys. Oceanogr., 32, 1779-1793, https://doi.org/ 10.1175/1520-0485(2002)032<1779:NEOTBO > 2.0.CO;2.

, and N. Stashchuk, 2007: Three-dimensional shoaling of large-amplitude internal waves. J. Geophys. Res., 112, C11018, https://doi.org/10.1029/2007JC004107.

Walter, R. K., C. Brock Woodson, R. S. Arthur, O. B. Fringer, and S. G. Monismith, 2012: Nearshore internal bores and turbulent mixing in southern Monterey Bay. J. Geophys. Res., 117, C07017, https://doi.org/10.1029/2012JC008115.

—, M. E. Squibb, C. B. Woodson, J. R. Koseff, and S. G. Monismith, 2014: Stratified turbulence in the nearshore coastal ocean: Dynamics and evolution in the presence of internal bores. J. Geophys. Res. Oceans, 119, 8709-8730, https://doi.org/10.1002/2014JC010396.

- M. Stastna, C. B. Woodson, and S. G. Monismith, 2016: Observations of nonlinear internal waves at a persistent coastal upwelling front. Cont. Shelf Res., 117, 100-117, https:// doi.org/10.1016/j.csr.2016.02.007.

Winters, K. B., P. N. Lombard, J. J. Riley, and E. A. D'Asaro, 1995: Available potential energy and mixing in density-stratified fluids. J. Fluid Mech., 289, 115-128, https://doi.org/10.1017/ S002211209500125X.

Woodson, C. B., 2018: The fate and impact of internal waves in nearshore ecosystems. Annu. Rev. Mar. Sci., 10, 421-441, https://doi.org/10.1146/annurev-marine-121916-063619. 